\title{
Supercooled interfacial water in fine-grained soils probed by dielectric spectroscopy
}

\author{
A. Lorek $^{1}$ and N. Wagner ${ }^{2}$ \\ ${ }^{1}$ German Aerospace Center (DLR), Berlin, Germany \\ ${ }^{2}$ Institute of Material Research and Testing at the Bauhaus-University Weimar, Weimar, Germany \\ Correspondence to: A. Lorek (andreas.lorek@dlr.de) \\ Received: 25 February 2013 - Published in The Cryosphere Discuss.: 9 April 2013 \\ Revised: 26 September 2013 - Accepted: 16 October 2013 - Published: 6 December 2013
}

\begin{abstract}
Water substantially affects nearly all physical, chemical and biological processes on the Earth. Recent Mars observations as well as laboratory investigations suggest that water is a key factor of current physical and chemical processes on the Martian surface, e.g. rheological phenomena. Therefore it is of particular interest to get information about the liquid-like state of water on Martian analogue soils for temperatures below $0^{\circ} \mathrm{C}$. To this end, a parallel plate capacitor has been developed to obtain isothermal dielectric spectra of fine-grained soils in the frequency range from $10 \mathrm{~Hz}$ to $1.1 \mathrm{MHz}$ at Martian-like temperatures down to $-70^{\circ} \mathrm{C}$. Two Martian analogue soils have been investigated: a Ca-bentonite (specific surface of $237 \mathrm{~m}^{2} \mathrm{~g}^{-1}$, up to $9.4 \% w / w$ gravimetric water content) and JSC Mars 1, a volcanic ash (specific surface of $146 \mathrm{~m}^{2} \mathrm{~g}^{-1}$, up to $7.4 \% \mathrm{w} / \mathrm{w}$ ). Three soil-specific relaxation processes are observed in the investigated frequency-temperature range: two weak highfrequency processes (bound or hydrated water as well as ice) and a strong low-frequency process due to counter-ion relaxation and the Maxwell-Wagner effect. To characterize the dielectric relaxation behaviour, a generalized fractional dielectric relaxation model was applied assuming three active relaxation processes with relaxation time of the $i$ th process modelled with an Eyring equation. The real part of effective complex soil permittivity at $350 \mathrm{kHz}$ was used to determine ice and liquid-like water content by means of the Birchak or CRIM equation. There are evidence that bentonite down to $-70^{\circ} \mathrm{C}$ has a liquid-like water content of 1.17 monolayers and JSC Mars 1 a liquid-like water content of 1.96 monolayers.
\end{abstract}

\section{Introduction}

Water is a key factor, especially in its liquid state, in nearly all physical, chemical and biological processes on the Earth. In contrast, Mars seems to be a dry desert planet where all processes involving water stopped millions of years ago. However, measurements of the atmospheric water vapour content (humidity) show a local distribution of possible precipitation of several micrometres (Smith, 2002). This available water as well as the observation of morning fog (Möhlmann et al., 2009) and ground frost (Viking Lander, 1979) clearly indicate the possibility of water sorption processes in the atmospheric layer near the planetary surface. Moreover, measurements of the total amount of water (chemically and physically bound, liquid as well as frozen) in certain surface areas suggest the possible occurrence of water in a range of up to $10 \%$ (Feldman, 2004). Recently observed rheological processes such as sedimentation and water percolation phenomena at dune slopes (Kereszturi et al., 2008, 2010) and a high oxidation state of material from the Martian surface (Möhlmann, 2004) give further indication of the existence of water. The outstanding role of a few monolayers of liquidlike water for the development of life is also shown in experimental investigations on terrestrial permafrost bacteria (Rivkina et al., 2000). This investigations show the possibility of metabolism with only a small amount of liquid water under extreme conditions. The mentioned works show that there is a lack of knowledge of the amount of water in the liquid state.

Against this background, Möhlmann (2008) developed a theoretical sandwich model for adsorption of water on mineral surfaces in soils. For an experimental verification 
and further refinement of the theoretical approach, there is the need to determine the amount of liquid-like water and ice in soil below $0^{\circ} \mathrm{C}$. There are several techniques available for the characterization of the binding state of water in porous materials: nuclear magnetic resonance (NMR - Watanabe and Mizoguchi, 2002; Stillman et al., 2010; Watanabe et al., 2011), atomic force microscopy (AFM Teschke et al., 2001), isothermal calorimetry (Anderson and Tiece, 1973) as well as broadband dielectric spectroscopy (BDS - Kaatze and Feldman, 2006). Especially the methods of broadband dielectric spectroscopy are sensitive for characterization of structural and dynamical properties of water in porous materials (Kupfer et al., 2005). At high frequencies typically above $1 \mathrm{MHz}$, the effective complex permittivity can be physically related to the amount of fluid-like water in the material based on mixture equations (Wagner et al., 2011). Therefore, different high-frequency electromagnetic (HF-EM, radio- to microwave) field methods were used for the characterization of water in soils such as time domain reflectometry (TDR), remote sensing methods or groundpenetrating radar (GPR - Hoekstra and Doyle, 1971; Delaney and Arcone, 1984; Seyfried and Murdock, 1996; Zhang et al., 2003; Yoshikawa and Overduin, 2005; Mironov et al., 2010). Especially HF-EM remote sensing techniques were used in planetary research, e.g. of Mars, such as satellitebased GPR (i.e. the MARSIS and SHARAD projects, Picardi et al., 2004; Seu et al., 2007), in cryospheric applications (e.g. Eisen et al., 2003, 2006) and in studies of permafrost soils (e.g. Wollschläger et al., 2010). However, the relaxation of interfacial water in the radio- to microwave frequency range is empirically estimated (Mironov et al., 2010). Furthermore, the quantitative determination of ice contents with HF-EM techniques in soils is limited due to the similar permittivity of ice $\varepsilon_{\text {I }}$ with 3.18 (Bohleber et al., 2012) in comparison to other solid soil phases. In the low-frequency range, the determination of the ice content is possible due to the relaxation frequency of ice in the $\mathrm{kHz}$ range (Grimm et al., 2008). In addition to the ice-relaxation process, further lowfrequency relaxation processes occur such as induced polarization, counter-ion relaxation and Maxwell-Wagner effects (Calvet, 1975; Ishida et al., 2000, 2003; Rotenberg et al., 2005; Leroy et al., 2008; Stillman et al., 2010), which provide additional useful information of the porous material.

Grimm et al. (2008) systematically studied low-frequency electrical properties of polycrystalline saline ice and salt hydrates in the frequency range from $1 \mathrm{mHz}$ to $1 \mathrm{MHz}$ and temperature range from -90 to $-3{ }^{\circ} \mathrm{C}$. The authors observe a decrease in activation energy with increasing ion concentration and therefore a shift in the relaxation time to lower values or to corresponding higher frequencies with concentration. In the study of Bittelli et al. (2004) dielectric measurements on three fine-grained soils in comparison to de-ionized polycrystalline ice in the frequency range from $100 \mathrm{~Hz}$ to $200 \mathrm{kHz}$ and temperature range from -30 to $5{ }^{\circ} \mathrm{C}$ were investigated. The results of the ice measurements are in good agreement with the results from the study of Auty and Cole (1952). Two relaxation processes were discussed: a low-frequency Maxwell-Wagner process as well as a relaxation process due to ice and liquid-like water. Maeno et al. (1992) separated ice and water relaxation based on the effective electrical conductivity at a frequency of $100 \mathrm{kHz}$. In recent broadband investigations by Stillman et al. (2010) on four soils (sand, glass powder, JSC Mars 1 and a Ca-bentonite), at least five relaxation processes were discussed. The appropriate amount of interface water was estimated with NMR measurements. However, the authors did not differentiate between adsorbed and hydrated water. Furthermore, a threephase mixture equation of the Lichtenecker and Rother type (cf. Wagner et al., 2011) is used to estimate the ice content in the case of the sand based on the quasi-static effective permittivity of the soil.

In this study, dielectric spectroscopy was carried out in the frequency range from $10 \mathrm{~Hz}$ to $1.1 \mathrm{MHz}$ and temperature range from -70 to $20^{\circ} \mathrm{C}$ for a systematic characterization of the state of water under Martian conditions. Two Marsanalogous soils were investigated: a clay soil (Ca-bentonite) and a volcanic ash (JSC-Mars 1). The dielectric relaxation behaviour was investigated based on a generalized fractional relaxation model assuming thermally activated processes. The real part of effective complex soil permittivity at $350 \mathrm{kHz}$ was used to separate ice and liquid-like water content by means of a power law mixture equation. The experimental results were used to analyse the theoretical sandwich model of water on mineral surfaces proposed by Möhlmann (2008).

\section{Theoretical background}

\subsection{The sandwich model of water on mineral surfaces}

In porous media like soils, two processes of ice melting (Dash et al., 2006) are responsible for the freezing point depression of interfacial water at the temperature $T_{\mathrm{S}}$ below the bulk freezing point of free water $T_{\mathrm{m}}(273.15 \mathrm{~K})$ : (i) the premelting of ice governed by van der Waals forces and (ii) the premelting of ice as a results of local curvatures and the pore geometry (cf. Gibbs-Thomson effect, Möhlmann, 2008). In the following we use the term "interfacial water" for the fraction of premelted liquid water.

Based on the theory of Hamaker (1937), Möhlmann (2008) developed a sandwich model that describes the interaction of van der Waals forces of two plan-parallel surfaces (soil, ice) and the interfacial water between. In combination with the Gibbs-Duhem relationship (Eq. 1), the model allows for the prediction of the thickness of a liquid-like water film in soils as a function of temperature below $T_{\mathrm{m}}$.

$L=\left(\frac{H \cdot T_{\mathrm{m}} \cdot v^{-3}}{6 \cdot \pi \cdot\left(T_{\mathrm{m}}-T_{\mathrm{S}}\right) \cdot \rho_{\mathrm{I}} \cdot q_{\mathrm{m}}}\right)^{1 / 3}$ 
Herein, $L$ is the number of monolayers, $T_{\mathrm{S}}$ the actual freezing point temperature $[\mathrm{K}], \rho_{\mathrm{I}}$ the ice density $\left[916.7 \mathrm{~kg} \mathrm{~m}^{-3}\right]$, $q_{\mathrm{m}}$ the enthalpy of fusion of ice $\left[333427 \mathrm{~J} \mathrm{~kg}^{-1}\right]$ (values cf. Chaplin, 2012), $H$ the Hamaker constant $[\mathrm{J}]$ and $v$ the the diameter of an monolayer of water $\left(3.5 \times 10^{-10} \mathrm{~m}-\right.$ cf. Möhlmann, 2008).

In this paper, we compare the predictions of the sandwich model with measurements from the capacitor system (Sect. 3.1). Considering that the number of observed monolayers was small (less than 2), only the freezing point depression by van der Waals forces was taken into account.

\subsection{Dielectric soil properties}

Based on Maxwell's equations of electrodynamics, broadband electromagnetic transfer functions of a soil sample can be defined in terms of complex relative effective permittivity

$\varepsilon_{\mathrm{r}, \mathrm{eff}}^{*}(\omega, T, p, \ldots)=\frac{\varepsilon_{\mathrm{eff}}^{*}(\omega, T, p, \ldots)}{\varepsilon_{0}}$

or effective conductivity

$\sigma_{\mathrm{eff}}^{*}(\omega, T, p, \ldots)=j \omega \varepsilon_{\mathrm{eff}}^{*}(\omega, T, p, \ldots)$

and complex relative effective magnetic permeability

$\mu_{\mathrm{r}, \mathrm{eff}}^{*}(\omega, T, p, \ldots)=\frac{\mu_{\mathrm{eff}}^{*}(\omega, T, p, \ldots)}{\mu_{0}}$,

with absolute complex permittivity $\varepsilon_{\text {eff }}^{*}$ or magnetic permeability $\mu_{\text {eff }}^{*}$, imaginary unit $j=\sqrt{-1}$, angular frequency $\omega=2 \pi f$ as well as permittivity $\varepsilon_{0}$ and magnetic permeability $\mu_{0}$ of free space. The transfer functions depend on frequency $\omega$ as well as on the thermodynamic state parameters such as temperature $T$, pressure $p$ and water content $w$ (cf. Wagner et al., 2011). In this study the magnetic permeability was not evaluated. In the case of the clay soil the assumption that magnetic effects can be neglected and relative magnetic permeability is equal to 1 is justified. The Martian analogue JSC Mars 1 contains magnetite phases. However, low-frequency measurements by Stillman and Olhoeft (2008) show that the real part of the relative magnetic permeability is less than 1.008 .

In order to parameterize the relaxation behaviour in dependence of the thermodynamic state parameters, a generalized broadband transfer function (generalized dielectric response - GDR) is suggested by Wagner et al. (2007):

$\varepsilon_{\mathrm{r}, \mathrm{eff}}^{*}(\omega)-\varepsilon_{\infty}=\sum_{i=1}^{N} \frac{\Delta \varepsilon_{i}}{\left(j \omega \tau_{i}\right)^{a_{i}}+\left(j \omega \tau_{i}\right)^{b_{i}}}-j \frac{\sigma_{\mathrm{DC}}}{\omega \varepsilon_{0}}$,

with $\varepsilon_{\infty}[-]$ the high-frequency limit of relative permittivity, $\Delta \varepsilon_{i}[-]$ the relaxation strength, $\tau_{i}$ [s] the relaxation time, $0 \leq a_{i}, b_{i} \leq 1[-]$ stretching exponents of the $i$ th process, and
$\sigma_{\mathrm{DC}}\left[\mathrm{S} \mathrm{m}^{-1}\right]$ direct current electrical conductivity. The relaxation time $\tau_{i}$ was assumed to depend on absolute temperature $T[\mathrm{~K}]$ and pressure $p[\mathrm{~Pa}]$ according to the Eyring equation:

$\tau_{i}(T, p)=\kappa_{i} \frac{h}{k_{\mathrm{B}} T} \exp \left(\frac{E_{\mathrm{a}, \mathrm{i}}(T, p)}{\mathrm{RT}}\right)$.

Herein, $h=6.62606957 \times 10^{-34} \mathrm{Js}$ denotes the Planck constant, $k_{\mathrm{B}}=1.3806488 \times 10^{-23} \mathrm{~J} \mathrm{~K}^{-1}$ the Boltzmann constant, $\kappa_{i} \approx 1$ the transmission coefficient and $R=$ $8.3144621 \mathrm{~J}(\mathrm{~mol} \mathrm{~K})^{-1}$ the gas constant. Activation energy is given by

$E_{\mathrm{a}, \mathrm{i}}(T, p)=\Delta G_{i}(T, p)+T \Delta S_{i}(T, p)$

where free enthalpy of activation or Gibbs energy $\Delta G_{i}(T, p)\left[\mathrm{kJ} \mathrm{mol}^{-1}\right]$ and entropy of activation of the $i$ th process $T \Delta S_{i}(T, p)\left[\mathrm{K} \mathrm{kJ}(\mathrm{K} \mathrm{mol})^{-1}\right]$ (Wagner et al., 2007; Wagner and Scheuermann, 2009).

Porous mineral materials consist mainly of four phases: solid particles (various mineral phases), pore air, pore fluid and a solid particle-pore fluid interface (Fig. 1). In principle the fractions of these phases vary both in space (due to composition and density) and time (due to changes of water content, porosity, pore water chemistry and temperature).

The electromagnetic properties of the solid particles can be assumed to be frequency independent in the considered temperature-pressure-frequency range. Real relative permittivity $\varepsilon_{\mathrm{G}}$ of inorganic dielectric mineral materials varies from 2 to 15 (cf. Schoen, 1996; Campbell, 2002; Olhoeft, 1974; Behari, 2005; Robinson, 2003, 2004a, b). However, the available data sets are restricted to limited frequency and temperature ranges and appropriate external measurement conditions were mostly not provided. Hence, the results obtained by different groups vary considerably. This suggests further systematic investigations with broadband electromagnetic techniques under controlled boundary conditions.

The pore fluid as well as the interface fluid can be considered as an aqueous solution with a temperaturepressure-frequency-dependent relative complex permittivity $\varepsilon_{\mathrm{W}}^{*}(\omega, T, p)$ according to the modified Debye model (Kaatze, 2007a) as a special case of the GDR according to Eq. (5) with $N=1, a_{i}=0$ and $b_{i}=1$ :

$$
\begin{aligned}
\varepsilon_{\mathrm{W}}^{*}(\omega, T, p)-\varepsilon_{\infty}(T, p) & =\frac{\varepsilon_{\mathrm{S}}(T, p)-\varepsilon_{\infty}(T, p)}{1+j \cdot \omega \cdot \tau(T, p)} \\
& -j \cdot \frac{\sigma_{\mathrm{DC}}(T, p)}{\omega \cdot \varepsilon_{0}},
\end{aligned}
$$

with static permittivity $\varepsilon_{\mathrm{S}}(T, p)$. Under atmospheric conditions the dielectric relaxation time of water $\tau(T)$ depends on temperature $T$ according to the Eyring equation (6) (cf. Buchner et al., 1999). Furthermore, Gibbs energy of the interface fluid $\Delta G_{\mathrm{d}}^{\#}(T)$ is a function of the distance from the particle surface (for quantitative approaches see Wagner and Scheuermann, 2009). The greatest upper limit of 


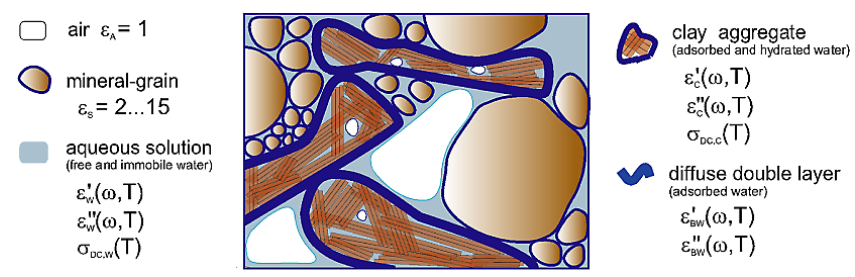

Fig. 1. Simplified schematic illustration of the structure of an unsaturated soil sample: indicated are the contributions of the single components to the dielectric material properties in terms of a complex effective relative permittivity $\varepsilon_{\mathrm{r}, \mathrm{eff}}^{*}=\varepsilon_{\mathrm{r}, \mathrm{eff}}^{\prime}-j \cdot \varepsilon_{\mathrm{r}, \mathrm{eff}}^{\prime \prime}$ with real $\varepsilon_{\mathrm{r}, \mathrm{eff}}^{\prime}$ and imaginary part $\varepsilon_{\mathrm{r}, \mathrm{eff}}^{\prime \prime}$ (cf. Wagner and Scheuermann, 2009).

$60.8 \mathrm{~kJ} \mathrm{~mol}^{-1}$ is equal to the free enthalpy of activation of ice (Bockris et al. 1963) and therefore corresponds to relaxation times in the $\mathrm{kHz}$ range. However, a lowest limit for the first molecular water layer in soils was suggested by Or and Wraith (1999) with $18 \mathrm{~kJ} \mathrm{~mol}^{-1}$ at $293.15 \mathrm{~K}$, which corresponds to relaxation times in the $\mathrm{GHz}$ range. An additional aspect was mentioned by the investigation of Buehler et al. (2011) in relation to the relaxation behaviour of the free pore solution. The authors proposed low-frequency relaxation processes according to the seminal works by Falkenhagen (1931) of the aqueous solution in relation to the ion concentration and speciation. Hence, the effective electromagnetic transfer function of the porous mineral material in terms of effective complex permittivity $\varepsilon_{\mathrm{r}, \mathrm{eff}}^{*}=\left(\Theta_{\mathrm{W}}, n, \rho_{\mathrm{i}}, \omega, T, p\right)$ is a function of volumetric water content $\Theta_{\mathrm{W}}$, porosity $n$, ion speciation and concentration $\rho_{\mathrm{i}}$, frequency $\omega=2 \pi f$, temperature $T$ and pressure $p$. In Wagner et al. (2011) several broadband approaches were discussed to model $\varepsilon_{\text {r.eff }}^{*}$. The authors concluded that the class of power law models based on an advanced Lichtenecker and Rother-type mixture equation (ALRM) provides a useful approach in applications:

$$
\begin{aligned}
\varepsilon_{\mathrm{r}, \mathrm{eff}}^{* a(\Theta, n)}\left(\Theta_{\mathrm{W}}, n, \rho_{\mathrm{i}}, \omega, T, p\right) & =\Omega_{a\left(\Theta_{\mathrm{W}}, n\right)}\left(\rho_{\mathrm{i}}, \omega, T, p\right) \\
& +(1-n) \cdot \varepsilon_{\mathrm{G}}^{a\left(\Theta_{\mathrm{W}}, n\right)}+\left(n-\Theta_{\mathrm{W}}\right) .
\end{aligned}
$$

The parameter $0 \leq a \leq 1$ contains structural information of free and interfacial water, and the term $\Omega_{a\left(\Theta_{\mathrm{W}, n)}\right.}\left(\rho_{\mathrm{i}}, \omega, T, p\right)$ represents the contribution of relaxation processes. In combination with Eq. (8), in the case of a simple material behaviour without strong relaxation processes, the term reads (see Wagner et al., 2011)

$\Omega_{a\left(\Theta_{\mathrm{W}, n)}\right.}=\Theta_{\mathrm{W}} \varepsilon_{\mathrm{W}}^{* a\left(\Theta_{\mathrm{W}}, n\right)}$.

Zakri et al. (1998) provide the theoretical justification of the ALR model based on effective medium theory with a distribution of depolarization factors linked to the structure parameter $a$. The ALR model is frequently used with $a=0.5$ (Robinson et al., 2003; Huisman et al., 2003; Loeffler and Bano, 2004), and is then called the complex refractive index model (CRIM), Birchak model (Birchak et al., 1974) or generalized refractive mixing dielectric model (GRMDM Mironov et al., 2004). For $a=1 / 3$, Eq. (9) transforms into the Looyenga-Landau-Lifschitz model (LLLM - Landau and Lifshitz, 1993; Campbell, 1990). Furthermore, Wagner et al. (2011) have pointed out that the exponent can vary between 0.2 and 0.8 with increasing volumetric water content. The following values were suggested in specific applications for a wide range of soil types: 0.46 (Roth et al., 1990) and 0.65 (Dobson et al., 1985), as well as 0.39 and 1.0 (Dirksen and Dasberg, 1993). In this study the CRIM or Birchak approach with $a=0.5$ is used. Moreover, the electromagnetic properties of the interfacial water phase in soils are poorly understood and therefore are difficult to quantify (cf. Wagner and Scheuermann, 2009). In practical applications the interfacial water phase is therefore neglected or crudely approximated (Schwartz et al., 2009). The mostly negative surface charge of the mineral surface (silicates) in contact with an aqueous electrolyte solution results in the formation of a boundary layer (electrical double layer - EDL). In principle, the interface layer consists of the surface charge of the mineral and an equivalent number of so-called counterions in the free electrolyte (Merriam, 2007). Tieleman and Berendsen (1996) stated that water molecules are ordered at the mineral surface according to two principles: (i) they effectively compensate for the local dipolar charge distribution of the surface molecules, and (ii) they reorient themselves due to the geometric constraints of the surface. Furthermore, Teschke et al. (2001) pointed out that the water molecules closest to the mineral surface orient themselves under optimization of their inter-water hydrogen bonds. This suggests there exists a more aligned molecular distribution in the interface region between mineral surface and bulk water than in the bulk, and consequently a layer with a lower effective permittivity than in the bulk. Teschke et al. (2001) suggested an expression proposed by Podgornik et al. (1987) based on Hamaker theory for the dependence of the static dielectric permittivity at atmospheric conditions as a function of the distance from a mica particle surface:

$\varepsilon_{\mathrm{S}}(d, T)=\frac{\varepsilon_{S, f}(T)}{1+\left(\frac{\varepsilon_{S, f}(T)}{\varepsilon_{S, p}(T)}-1\right) \cdot \exp \left(-\frac{2 d}{\lambda}\right)}$,

with static free-water permittivity $\varepsilon_{S, f}(T)$, static permittivity at the particle surface $\varepsilon_{S, p}(T)$, distance from the surface $d$ and correlation length $\lambda$.

Due to the low water content of the materials only interface water was considered in this study. Hence, under atmospheric conditions Eq. (9) was used in three-phase form with air, solid particles and interface water:

$$
\begin{aligned}
\varepsilon_{\mathrm{r}, \mathrm{eff}}^{* 0.5}\left(\Theta_{\mathrm{W}}, n, \omega, T\right) & =\Theta_{\mathrm{W}} \cdot \varepsilon_{\mathrm{W}}^{* 0.5}(\omega, T) \\
& +\Theta_{\mathrm{G}} \cdot \varepsilon_{\mathrm{G}}^{0.5}+\Theta_{A} \cdot \varepsilon_{A}^{0.5},
\end{aligned}
$$

with unknown permittivity $\varepsilon_{\mathrm{G}}$ of the solid phase, the permittivity of air $\varepsilon_{A}=1$, complex permittivity of water $\varepsilon_{\mathrm{W}}^{*}$, the 
volume fraction of the solid phase $\Theta_{\mathrm{G}}=1-n$ and volumetric air content $\Theta_{A}=1-\Theta_{\mathrm{W}}-\Theta_{\mathrm{G}}$. $\varepsilon_{\mathrm{G}}$ was estimated based on empirical equations according to Olhoeft (1974), Campbell (2002) or Dobson et al. (1985) as well as from the mineralogical composition according to Robinson (2004a) with data from Schoen (1996) for the single mineral phases. Moreover, $\varepsilon_{\mathrm{G}}$ was determined from the permittivity of the dry material with

$\varepsilon_{\mathrm{G}}=\left(\frac{\varepsilon_{\mathrm{r}, \mathrm{eff}}^{* 0.5}-\Theta_{A}-\Theta_{\mathrm{W}} \cdot \varepsilon_{\mathrm{W}}^{0.5}}{\Theta_{\mathrm{G}}}\right)^{2}$.

\section{Experimental procedure}

\subsection{Experimental setup}

The developed gas-sealed parallel plate capacitor consists of circular capacitor plates with a guard ring electrode (Lorek, 2008). Due to the resulting parallel electric field (Rost, 1978) and a well-defined air gap between investigated soils and the upper electrode, permittivity measurements on fine-grained powdered materials are possible (Fig. 2; Agilent, 2000). The measurements were performed in a wide temperature regime from -70 to $25^{\circ} \mathrm{C}$.

At $25{ }^{\circ} \mathrm{C}$ the gold-coated polished brass plates have a distance of $1.26 \mathrm{~mm}$. The resulting fractions are for the air gap $d_{1}=0.45 \mathrm{~mm}$ and for the soil $d_{2}=0.81 \mathrm{~mm}$. The lower plate has a diameter of $90 \mathrm{~mm}$ and is located in a cavity with a diameter $d_{3}$ of $91 \mathrm{~mm}$. The distance between this plate and the upper brim of the cavity is the soil height $d_{2}$. The upper plate has a diameter $d_{\mathrm{KP}}$ of $77.56 \mathrm{~mm}$. The volume for the soil sample inside the capacitor $\theta_{\text {Soil }}$ is $5.268 \mathrm{~cm}^{3}$.

The housing material is a hydrophobic polycarbonate (Makrolon), a material with permanent mechanical load capacity down to $-50^{\circ} \mathrm{C}$ (PVDF, 2003). The housing has integrated gas inlets and outlets and is gas sealed with silicon rubber zero rings. These are at least cold resistant down to $-60^{\circ} \mathrm{C}$ (RALICKS, 2012).

The absolute value $\left|\varepsilon_{\mathrm{r} \text {,eff }}^{*}\right|$ of the complex relative effective permittivity $\varepsilon_{\mathrm{r}, \text { eff }}^{*}$ is determined for a capacitor with circular plates and the capacities $C_{\mathrm{Gas}}$ and $C_{\text {Soil }}$ connected in serial based on (see definitions in Fig. 2)

$\left|\varepsilon_{\mathrm{r}, \mathrm{eff}}^{*}\right|=\frac{d_{2} \cdot C \cdot \varepsilon_{\mathrm{G}}}{\varepsilon_{A} \cdot \varepsilon_{0} \cdot \frac{\pi}{4} \cdot d_{\mathrm{KP}}^{2}-d_{1} \cdot C}$,

with capacitance $C$ of the plate capacitor. $\varepsilon_{\mathrm{r}, \mathrm{eff}}^{\prime}$ and $\varepsilon_{\mathrm{r}, \mathrm{eff}}^{\prime \prime}$, the real and imaginary part of $\varepsilon_{\mathrm{r}, \mathrm{eff}}^{*}$, respectively, are given with the measured loss factor $\tan \delta_{\text {eff }}$ (cf. Lorek, 2008):

$\varepsilon_{\mathrm{r}, \mathrm{eff}}^{\prime}=\left|\varepsilon_{\mathrm{r}, \mathrm{eff}}^{*}\right| \cdot\left(\tan \delta_{\mathrm{eff}}^{2}+1\right)^{-0.5}$,

$\varepsilon_{\mathrm{r}, \mathrm{eff}}^{\prime \prime}=\left|\varepsilon_{\mathrm{r}, \mathrm{eff}}^{*}\right| \cdot \tan \delta_{\mathrm{eff}}\left(\tan \delta_{\mathrm{eff}}^{2}+1\right)^{-0.5}$.

Figure 3 shows the entire experimental setup. For defined temperatures, the capacitor was placed in a thermal test

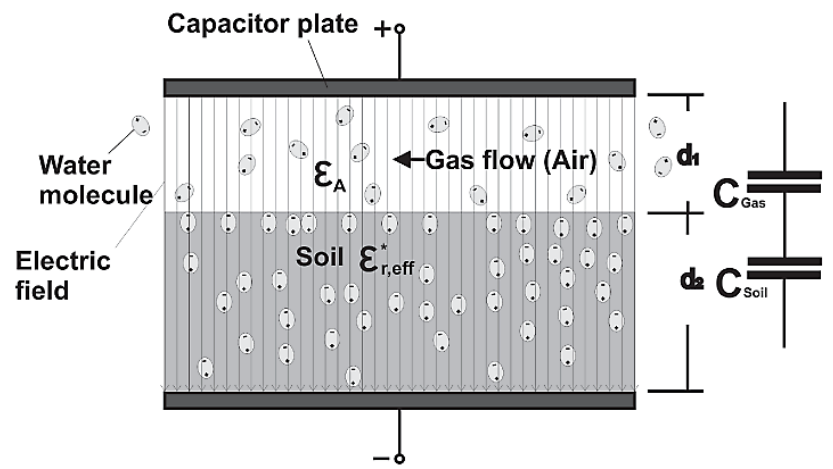

Fig. 2. Schematic diagram of the capacitor with defined air gap over investigated material.

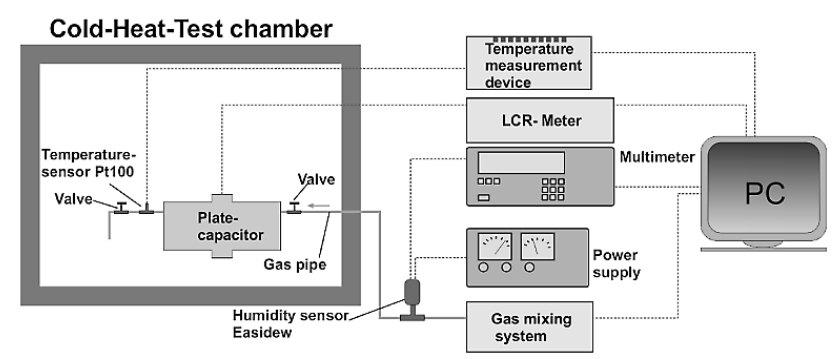

Fig. 3. Measurement system.

chamber (KWP 240, Weiss $\mathrm{GmbH}$ ) at a defined temperature. For the measurement at 62 different frequencies between $10 \mathrm{~Hz}$ and $1.1 \mathrm{MHz}$, a LCR bridge (PSM 1700 PsimetriQ, Newtons4th Ltd (UK)) was used. To set the investigated soil on a defined value of moisture, a gas flow of $15 \mathrm{~L} \mathrm{~h}^{-1}$ with an absolute humidity of ca. $0.00193 \mathrm{~g} \mathrm{~m}^{-3}$ at $25^{\circ} \mathrm{C}$ was applied through the air gap (Fig. 2). The humidity was determined by an Easidew dew point transmitter (Michell Instruments $\mathrm{GmbH})$. Reaching the required soil moisture and vice versa the corresponding capacity, the gas inlets and outlets of the capacitor were closed.

Next, the chamber temperature was first isothermally decreased in 5 and $10 \mathrm{~K}$ steps to the lowest temperature of $-70{ }^{\circ} \mathrm{C}$ and then isothermally increased using the same step sizes. For every step the temperature was stabilized for $5 \mathrm{~h}$. On this, capacitor and test material had time to reach thermal equilibrium, confirmed by stable capacity values. Measurement of gas temperature was performed with a Pt100 temperature sensor after the gas stream has passed the capacitor.

After the experiment, the soil was completely removed to identify the gravimetric water content (Sect. 3.3). The measurements with the clay soil were carried out for three water contents: 1.53 monolayers $(9.4 \% w / w), 1.17$ monolayers $(7.2 \% w / w)$ and 0.7 monolayers $(4.3 \% w / w)$. The experiments with JSC Mars 1 samples were done with 1.96 monolayers $(8.7 \% w / w), 1.71$ monolayers $(7.6 \% w / w)$ and 1.37 monolayers $(6.1 \% w / w)$. 


\subsection{Investigated soils}

\subsubsection{Swelling clay soil}

The clay soil is based on a commercially available Cabentonite (Edasil, Agrimont $\mathrm{GmbH}$ ). This bentonite mainly contains Ca-dioctahedral smectites, i.e. montmorillonite, which are swelling clay minerals. Surface areas consisting of similar swelling clay minerals have been detected on Mars (Poulet et al., 2005). Because of their formation history these areas are preferred as possible habitats of former or current life on Mars (Chevrier and Mathe, 2007). Table 1 shows measured and published values for the used powdered $\mathrm{Ca}$ bentonite.

The high montmorillonite content leads to a relatively large surface with $74 \mathrm{~m}^{2} \mathrm{~g}^{-1}$ (BET surface area with $\mathrm{N}_{2}$ ) (Jänchen et al., 2009b). Studies on montmorillonite using the BET method with water in place of nitrogen have shown a surface enlargement to $217 \mathrm{~m}^{2} \mathrm{~g}^{-1}$ (Jänchen et al., 2009a). This finding was confirmed by the measured specific surface areas of the investigated clay soil.

\subsubsection{Volcanic ash}

JSC Mars 1 is a volcanic ash from Mauna Kea (Hawaii) and defined as a Mars analogue material (Allen et al., 1998). The natural grain sizes of $800-1000 \mu \mathrm{m}$ were too large for the capacitor. Therefore, the soil was crushed and fractionated to certain sizes. To determine differences to the original material (Table 2), the fractions were analysed individually.

\subsection{Sample preparation}

At constant temperature and humidity, multiple samples from the clay and JSC Mars 1 were prepared. The prepared samples have an equivalent dry density $\rho_{D}$ and thus comparable soil surface areas $S$. The gravimetric water content $\theta_{G}$ was determined by drying the sample for $24 \mathrm{~h}$ at $105^{\circ} \mathrm{C}$ in air atmosphere (Wernecke, 2003; Scheffer and Schachtschabel, 1989). All measurements described in this paper were done on samples prepared according to this procedure.

The average weight of the clay samples in the capacitor was $4.185 \pm 0.01 \mathrm{~g}$ with a gravimetric water content of about $9.27 \% w / w$. From this results a dry soil content $m_{\mathrm{G}}$ of $3.83 \pm 0.01 \mathrm{~g}$ clay and a surface area $S$ of $908 \pm 2 \mathrm{~m}^{2}$ (with a specific surface area $S_{\mathrm{sp}}$ of $237 \mathrm{~m}^{2} \mathrm{~g}^{-1}$, c.f. Table 1). The weight of a monomolecular water layer is $2.6 \times 10^{-4} \mathrm{~g} \mathrm{~m}^{-2}$ (Hauffe and Morrison, 1974), which corresponds to a gravimetric water content per monolayer of $6.16 \% \mathrm{w} / \mathrm{w}$.

Each sample was completely connected to the lower capacitor plate, spread evenly and pressure less smoothed to avoid fluctuations in density and thickness. After the experiment, the capacitor was opened, the material promptly placed into a covered sample dish and the weight then determined. The resulting difference due to the adsorption of water from surrounding air while extracting and weighing the samples was less than $3 \%$ of the measured gravimetric water content.

For JSC Mars 1 the fraction with grain sizes of 32-63 $\mu \mathrm{m}$ (Sect. 3.2) was optimal for the homogeneous distribution in the capacitor. This fraction has compared to the original soil a larger specific surface area. Due to the assumption of more fine dust in the first few millimetres of the Martian surface the use of this fraction is reasonable.

The average weight of JSC Mars 1 samples was $4.252 \pm 0.05 \mathrm{~g}$. The negligible difference of $3.3 \%$ in the gravimetric water content can be explained with the absorption of water from the ambient humidity during extraction and weighing. The samples had a gravimetric water content of about $9.81 \% \mathrm{w} / \mathrm{w}$. This leads to a $m_{\mathrm{G}}$ value of $3.872 \pm 0.05 \mathrm{~g}$ and an $S$ value of $662 \pm 28 \mathrm{~m}^{2}$. One monolayer of water corresponds to a gravimetric water content of $4.45 \% w / w$.

\section{Experimental results}

Figure 4a (left) shows $\varepsilon_{\text {reff }}^{\prime}$ (Eq. 15) and $\varepsilon_{\text {r.eff }}^{\prime \prime}$ (Eq. 16) of the soils at the highest investigated water content in a temperature range from -70 to $20^{\circ} \mathrm{C}$. A direct indication for freezing is not observable, especially in the case of the volcanic ash. In $\varepsilon_{\mathrm{r} \text {,eff }}^{\prime \prime}$ an additional relaxation peak is expected for freezing in the frequency range $<10 \mathrm{kHz}$ and below $0{ }^{\circ} \mathrm{C}$ (Ulaby et al., 1986; cf. Lorek, 2008). However, in the case of the clay soil there exists a strong relaxation peak even at $20^{\circ} \mathrm{C}$ which shifts with decreasing temperature to lower frequencies.

In Fig. 4a (right) the data set is represented in addition as a complex electric modulus (Jonscher, 1983) to separate different relaxation mechanisms:

$$
M^{*}=\frac{1}{\varepsilon_{\mathrm{r}, \mathrm{eff}}^{*}}=\frac{1}{\varepsilon_{\mathrm{r}, \mathrm{eff}}^{\prime}-\varepsilon_{\mathrm{r}, \mathrm{eff}}^{\prime \prime}}=\frac{\varepsilon_{\mathrm{r}, \mathrm{eff}}^{\prime}}{\varepsilon_{\mathrm{r}, \mathrm{eff}}^{\prime 2}-\varepsilon_{\mathrm{r}, \mathrm{eff}}^{\prime \prime 2}}+j \cdot \frac{\varepsilon_{\mathrm{r}, \mathrm{eff}}^{\prime \prime}}{\varepsilon_{\mathrm{r}, \mathrm{eff}}^{\prime 2}-\varepsilon_{\mathrm{r}, \mathrm{eff}}^{\prime \prime 2}} .
$$

The dielectric relaxation behaviour was analysed with three different methods: (i) based on the temperature dependence of characteristic frequencies such as the maximum frequency in the imaginary part of the complex effective permittivity, (ii) based on the inverse modelling technique by means of fitting the frequency dependency of the complex permittivity at each measured temperature, and (iii) a simultaneous fit of the frequency and temperature dependence.

With the approach in (i) it was assumed that the temperature dependence of a characteristic frequency $f_{r}$ is related to the relaxation time $f_{r}=(2 \cdot \pi \cdot \tau)^{-1}$. Then, the appropriate activation energy was determined with an Arrhenius approach in Eyring equation (6):

$\tau_{i}(T)=\tau_{0, i} \cdot \exp \left(\frac{E_{a, i}}{R \cdot T}\right)$.

Using this approach, apparent activation energy $E_{a, i}=\Delta G_{i}$ is assumed to be constant. An appropriate pre-factor is then 
Table 1. (1) Excerpt from Edasil data sheet (Agrimont $\mathrm{GmbH}$ ); (2) soil parameters for bentonite (BET method with $\mathrm{N}_{2}$ and $\mathrm{H}_{2} \mathrm{O}$ measurement performed at the Federal Institute for Materials Research and Testing (BAM)).

\begin{tabular}{ll|ll}
\hline Montmorillonite & & Chemical composition & Mass \% \\
\cline { 3 - 4 } Cation exchange capacity $\mathrm{Na}^{1}$ & $0.65 \mathrm{mmolL}^{-1}$ & $\mathrm{SiO}_{2}$ & 56 \\
$\mathrm{CI}^{1}$ & $1.09 \mathrm{mmol} \mathrm{L}^{-1}$ & $\mathrm{Al}_{2} \mathrm{O}_{3}$ & 16 \\
Grain size $<63 \mu \mathrm{m}^{1}$ & $90-93 \%$ & $\mathrm{Fe}_{2} \mathrm{O}_{3}, \mathrm{CaO}, \mathrm{MgO}$ & every 4 \\
Grain size $>63 \mu \mathrm{m}^{1}$ & $7-10 \%$ & $\mathrm{~K}_{2} \mathrm{O}$ & 2 \\
Spec. surface $\left(\mathrm{N}_{2}^{2}\right)$ & $50.3 \mathrm{~m}^{2} \mathrm{~g}^{-1}$ & $\mathrm{Na}_{2} \mathrm{O}$ & 0.4 \\
Spec. surface $\left(\mathrm{H}_{2} \mathrm{O}^{2}\right)$ & $237 \mathrm{~m}^{2} \mathrm{~g}^{-1}$ & & \\
Pore size & $5.641 \mathrm{~nm}^{2}$ & & \\
Absolute density & $2.38 \mathrm{~g} \mathrm{~cm}^{-3}$ & & \\
\hline
\end{tabular}

Table 2. Density, specific surface and pore size of the JSC Mars 1 - fractions (measurements performed at BAM).

\begin{tabular}{llrrrr}
\hline Fraction & Unit & Original & $<25 \mu \mathrm{m}$ & $25-32 \mu \mathrm{m}$ & $32-63 \mu \mathrm{m}$ \\
\hline Spec. surface area (BET method $\left.\mathrm{N}_{2}\right)$ & $\mathrm{m}^{2} \mathrm{~g}^{-1}$ & $123.7 \pm 0.3$ & $148.9 \pm 0.3$ & $156.1 \pm 0.4$ & $145.8 \pm 0.4$ \\
Spec. surface area (BET method $\left.\mathrm{H}_{2} \mathrm{O}\right)$ & $\mathrm{m}^{2} \mathrm{~g}^{-1}$ & & & & $171 \pm 5$ \\
Porosity & $\%$ & 67.0 & 62.9 & 63.2 & 61.2 \\
Pore size BET (N2) & $\mathrm{nm}$ & 4.4 & 4.14 & 3.98 & 4.05 \\
Pore size $\emptyset(\mathrm{Hg})$ & $\mathrm{nm}$ & 94.1 & 80.6 & 80.2 & 81.1 \\
Absolute density & $\mathrm{g} \mathrm{cm}^{-3}$ & 2.65 & 2.62 & 2.59 & 2.64 \\
\hline
\end{tabular}
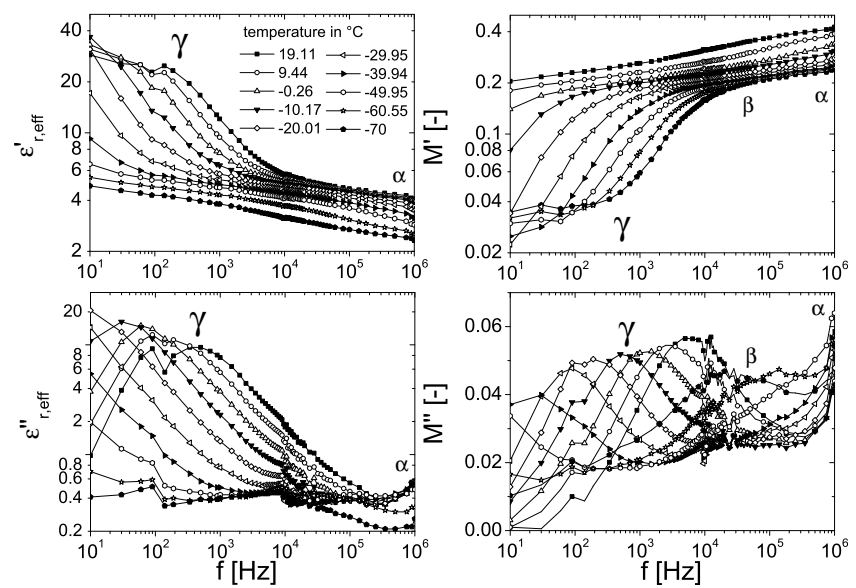

Fig. 4a. (Top) real part and (bottom) imaginary part of the complex effective permittivity $\varepsilon_{\mathrm{r} \text {,eff }}^{*}$ or complex modulus $M^{*}=1 / \varepsilon_{\mathrm{r}, \mathrm{eff}}^{*}$ of the clay sample in the case of a constant water content of 1.53 monolayers water measured in the temperature range from -70 to $20^{\circ} \mathrm{C}$.

given by $\tau_{0, i}=\frac{h}{k_{\mathrm{B}} \cdot T} \cdot \exp \left(\frac{\Delta S_{i}}{R}\right)$. Here the temperature independence of $\Delta G_{i}$ and $\Delta S_{i}$ is further implied. The prefactor obtained with the modulus representation is related to $\tau_{0, i}$ with a scaling term $\delta$. For a Cole-Cole-type relaxation function the relationship is given by $\tau_{0, i}^{\prime}=\delta \tau_{0, i}=$ $\left(\varepsilon_{\infty} / \varepsilon_{S}\right)^{1 / a} \tau_{0, i}$ (Richert, 2000; Ito and Richert, 2005). In a representation of the logarithm of an appropriate relaxation time or characteristic frequency $y=\ln \left(\tau_{i}\right)=-\ln \left(2 \pi f_{r, i}\right)$ as
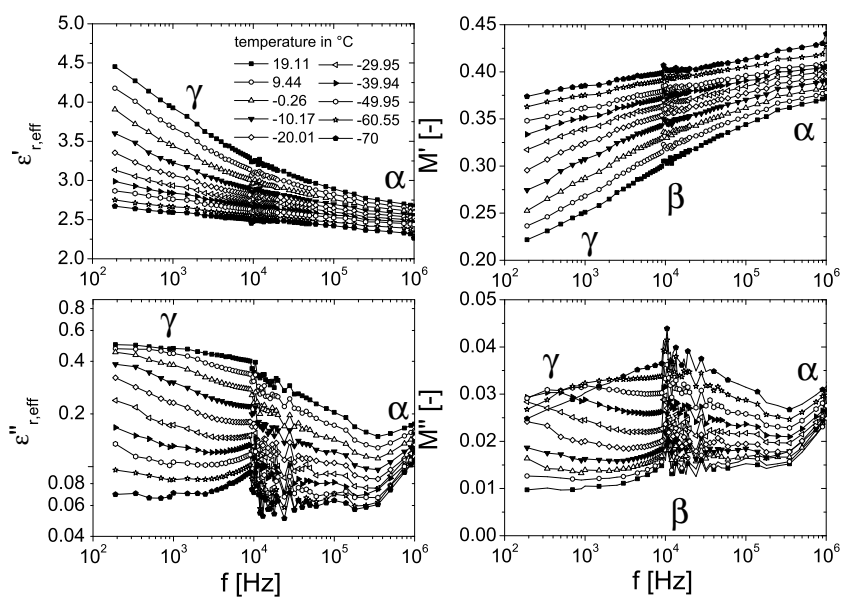

Fig. 4b. Complex effective permittivity $\varepsilon_{\mathrm{r}, \mathrm{eff}}^{*}$ or complex modulus $M^{*}=1 / \varepsilon_{\mathrm{r}, \mathrm{eff}}^{*}$ of the volcanic ash at a constant water content of 1.96 monolayers.

a function of reciprocal temperature $x=T^{-1}$, Eq. (18) transforms into a linear equation $y=A_{i}+B_{i} \cdot x$. This equation was then fitted to the relaxation times obtained from the characteristic frequencies $f_{r, i}(T)$ of the maxima in the imaginary part of the complex modulus as a function of temperature. The offset $A$ is related to the pre-factor $A=\ln \left(\tau_{0}\right)$ and the slope to the apparent activation energy $B=E_{a} \cdot R^{-1}$. 


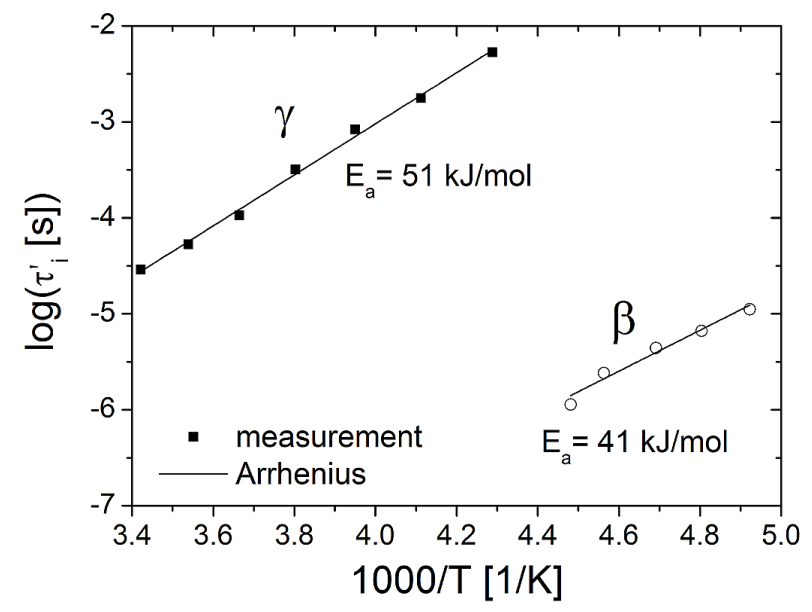

Fig. 5. Arrhenius representation of the relaxation time $\tau=f_{\max }^{-1}$ for the two processes $\beta$ and $\gamma$ obtained from the appropriate maximum frequency $f_{\max }$.

Approach (i) is not applied to the volcanic ash due to the weak dispersion. In Fig. 5 the results in the case of the clay soil are represented for the $\beta$ and $\gamma$ process. In Fig. 6 the resultant master curve representation of the data set in the temperature range from -20 to $19^{\circ} \mathrm{C}$ for the $\gamma$ process is given. From this representation of the data it becomes clear that the low-frequency $\gamma$ process cannot be modelled with a simple Debye equation. Here a Cole-Cole-type relaxation function is necessary. This means that the relaxation mechanism is characterized by a distribution of relaxation times $H(\tau)$. In this context, the determined relaxation time from the peak frequency is a mean macroscopic relaxation time related to the appropriate microscopic relaxation time due to the assumed relaxation model (Jonscher, 1983). Furthermore, the relaxation time distribution can change with temperature for measurements in a broad temperature range. Therefore the approach in (ii) is applied to the data set.

In case (ii), equation (GDR) is fitted to the data set based on Eq. (5) at each temperature using a shuffled complex evolution Metropolis algorithm (SCEM-UA - Vrugt, 2003). This algorithm is an adaptive evolutionary Monte Carlo Markov chain method and combines the strengths of the Metropolis algorithm, controlled random search, competitive evolution and complex shuffling to obtain an efficient estimate of the most optimal parameter set, as well as its underlying posterior distribution, within a single optimization run (Heimovaara et al., 2004).

The algorithm is based on a Bayesian inference scheme. The needed prior information is a lower and upper bound for each of the relaxation parameters $\xi$. Assuming this noninformative prior, the posterior density $p(\xi \mid y, \mu)$ for $\xi$ conditioned with the measurement $y$ is given by (Vrugt, 2003)

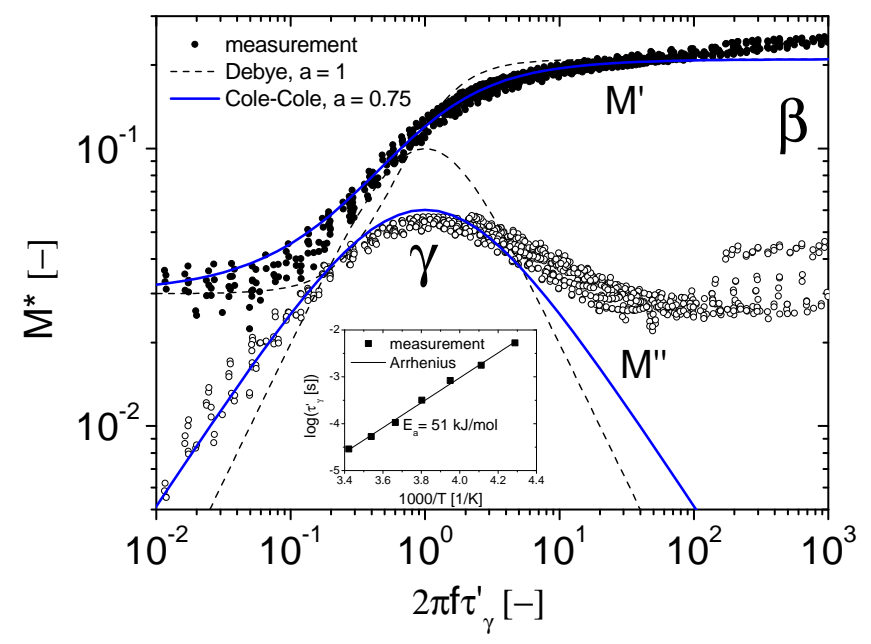

Fig. 6. Master curve of the complex modulus $M^{*}$ for the $\gamma$ process.

$p(\xi \mid y, \mu) \propto\left[\sum_{k=1}^{N} \frac{y_{k}-\hat{y}_{k}}{\delta}\right]^{-N(1+\mu) / 2}$.

Herein $y_{k}$ is the $k$ th of $m$ measurements at each frequency for a given temperature and $\hat{y}_{k}$ is the corresponding model prediction. $\delta$ represents the error of the measurements expressed as a standard deviation. The parameter $\mu$ specifies the error model of the residuals. The residuals are assumed normally distributed when $\mu=0$, double exponential when $\mu=1$ and tend to a uniform distribution as $\mu \rightarrow-1$. In (iii) the approach is extended to frequency and temperature. In Fig. 7 the results of these two approaches are represented. In Table 3 the results of the simultaneous analyses according to method (iii) for both soils are summarized.

For an analysis of the relaxation behaviour the measurements of the soils with highest water content (1.53 or 1.96 monolayers) was used (see Table 3 ). In the case of the clay soil the experimental results (Fig. 4a) indicate three relaxation processes in the investigated frequency-temperaturepressure range: two weak high-frequency processes $\alpha$ and $\beta$ (associated with different binding states of water in the porous material) and a strong low-frequency process $\gamma$ associated with counter-ion relaxation, Maxwell-Wagner effects and ice. For the analysis of the volcanic ash also, these three processes were used to model the relaxation behaviour regardless of the weak dispersion and no clear indication of a relaxation peak in the investigated frequency-temperaturepressure range. However, the results of the simultaneous analysis suggest a $\gamma$ process below the measurement window. The strong $\gamma$ process of the clay soil exhibits an apparent activation energy of $51 \mathrm{~kJ} \mathrm{~mol}^{-1}$ and shows a clear deviation from simple Debye behaviour. This is a clear indication of an overlapping of different relaxation mechanisms. Furthermore, the analysis of the relaxation behaviour indicates 
Table 3. Summary of the determined relaxation parameters of the two soils at the highest water content based on the simultaneous analyses according to method (iii).

\begin{tabular}{lrrrr}
\hline \multicolumn{1}{c}{ Clay soil } & \multicolumn{4}{c}{ JSC-Mars I } \\
\hline RMSE [-] & 0.26 & & 0.28 & \\
monolayers & 1.53 & & 1.96 & \\
$\varepsilon_{U}[-]$ & 1.90 & $( \pm 0.015)$ & 1.7 & $( \pm 0.05)$ \\
$\Delta \varepsilon_{\alpha}[-]$ & 0.005 & $( \pm 0.0002)$ & 0.003 & $( \pm 0.0001)$ \\
$E_{a, \alpha}\left[\mathrm{kJ} \mathrm{mol}^{-1}\right]$ & 32.00 & $( \pm 0.01)$ & 22.3 & $( \pm 2.1)$ \\
$1-a_{\alpha}[-]$ & 0 & - & 0 & - \\
$\Delta \varepsilon_{\beta}[-]$ & 5.21 & $( \pm 0.12)$ & 1.43 & $( \pm 0.07)$ \\
$E_{a, \beta}\left[\mathrm{kJ} \mathrm{mol}^{-1}\right]$ & 36.7 & $( \pm 0.4)$ & 39.8 & $( \pm 0.2)$ \\
$1-a_{\beta}[-]$ & 0.793 & $( \pm 0.005)$ & 0.875 & $( \pm 0.009)$ \\
$\Delta \varepsilon_{\gamma}[-]$ & 24.90 & $( \pm 0.38)$ & 10.8 & $( \pm 1.1)$ \\
$E_{a, \gamma}\left[\mathrm{kJ} \mathrm{mol}^{-1}\right]$ & 51.98 & $( \pm 0.06)$ & 67.7 & $( \pm 1.3)$ \\
$1-a_{\gamma}[-]$ & 0.153 & $( \pm 0.005)$ & 0.703 & $( \pm 0.007)$ \\
\hline
\end{tabular}

an increase of the relaxation time distribution with decreasing temperature (Fig. 8), which suggests that the relaxation time distribution is a measure of the coexistence of liquidlike water and ice.

The $\beta$ process is visible in the low-temperature range below $-50{ }^{\circ} \mathrm{C}$ with apparent activation energy of $41 \mathrm{~kJ} \mathrm{~mol}^{-1}$. For an analysis of the $\alpha$ process the frequency range has to be extended to higher frequencies. However, based on the inverse modelling technique, appropriate apparent activation energy of $32 \mathrm{~kJ} \mathrm{~mol}^{-1}$ was estimated. Furthermore, a narrow relaxation time distribution was observed. In Fig. 9 the results of the relaxation behaviour with the different approaches is represented in comparison to results of other studies. It becomes clear that the characterization of the observed relaxation processes is inconsistent. Investigations in the frequency range below $10 \mathrm{MHz}$ were carried out by Bergman and Swenson (2000) on a swelling clay (vermiculite) in the frequency range from $10 \mathrm{mHz}$ to $10 \mathrm{MHz}$, and temperature range from -140 to $-68^{\circ} \mathrm{C}$. The study aimed to characterize the relaxation behaviour of hydrated interlayer water. Three relaxation processes were observed and associated with a Maxwell-Wagner effect (low-frequency range), supercooled interlayer water (intermediate range) and ice (high frequency). In comparison, the authors performed measurements on pure ice which coincide with the highfrequency process.

Auty and Cole (1952), Johari and Jones (1976) and Bittelli et al. (2004) determined an activation energy of $55 \mathrm{~kJ} \mathrm{~mol}^{-1}$ for de-ionized ice, which is distinctly higher than $E_{a}$ obtained by Bergman and Swenson (2000) with $32 \mathrm{~kJ} \mathrm{~mol}^{-1}$. Hence, the association of the $\alpha$ process with ice relaxation seems to be reasonable in comparison to the results of dielectric spectroscopy on swelling clay by Bergman and Swenson (2000). However, the results are inconsistent with the results of de-ionized ice from Auty and Cole (1952), results of different soils by Bittelli et al. (2004) and those of contaminated
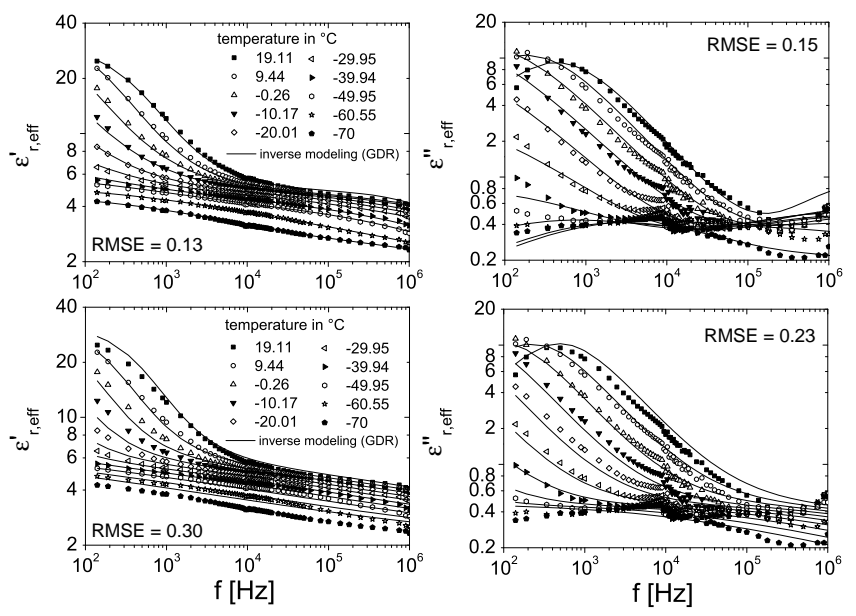

Fig. 7. Complex effective permittivity of the clay sample in the case of a constant water content of 1.53 monolayers water measured in the temperature range from -70 to $20^{\circ} \mathrm{C}$ parameterized with the GDR (top) at each temperature and (bottom) in combination with Eqs. (6) or (12) simultaneously.

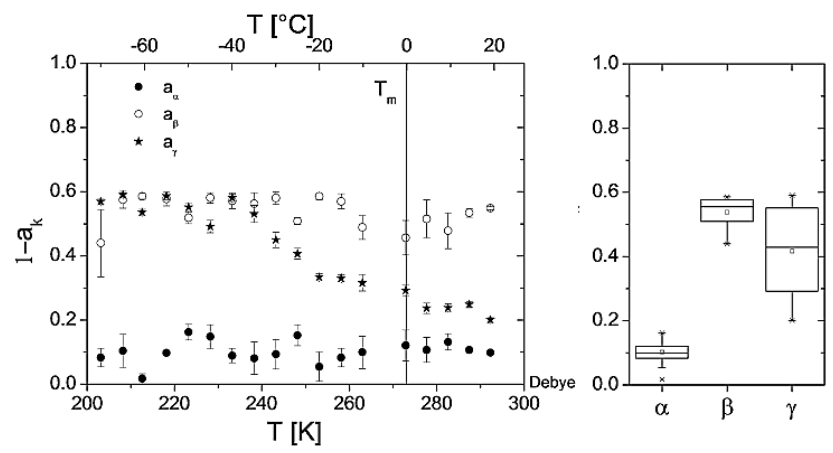

Fig. 8. Dependence of the distribution parameter $\alpha_{k}$ of the $k$ th process on temperature.

ice from Grimm et al. (2008). Moreover, the transition from free bulk water to supercooled interface water as a function of the distance from particle surface (Speedy and Angell, 1976; Swenson et al., 2002) as well the fast water reorientation (Sciortino et al., 1996; Buchner et al., 1999; Kaatze, $2007 \mathrm{a}, \mathrm{b}$ ) in soils were not sufficiently characterized. In the current development stage the bandwidth of the measurement systems is restricted and therefore the relaxation behaviour cannot be fully analysed. This issue needs to be addressed in further broadband studies. However, in this study, a mixture approach based on a power law model (CRIM) according to Eq. (12) is suggested to separate fluid-like water and ice at a measurement frequency of $350 \mathrm{kHz}$. In this frequency range two processes are active $(\beta, \gamma)$.

Figure 10 illustrates the temperature dependence of $\varepsilon_{\mathrm{r} \text {,eff }}^{\prime}$ for $0.7,1.17$ and 1.53 monolayers water at a frequency of $350 \mathrm{kHz}$. For this frequency the values have shown the lowest dielectric losses (Fig. 4a) and are sufficient to reflect the 


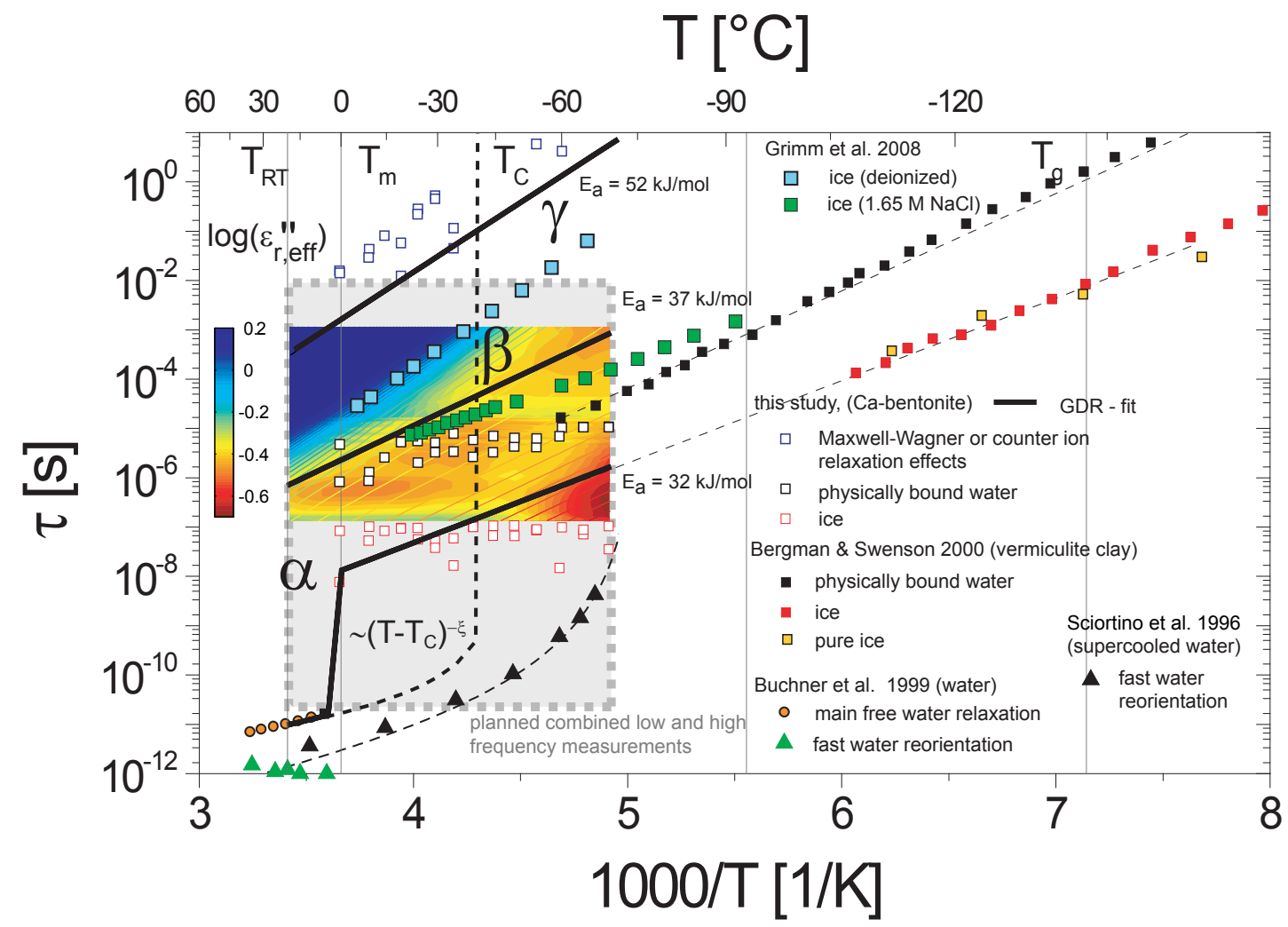

Fig. 9. Relaxation map of the Ca-bentonite (1.53 water monolayers) in comparison to results from aqueous solution with different electrolyte concentrations, ice and clay soils. The contour plot represents the measured imaginary part of the relative complex effective permittivity. $T_{R T}$ denotes room temperature, $T_{m}$ is the melting temperature, $T_{S}=228 \mathrm{~K}$ is the critical temperature with critical exponent $\xi=1.55$, and $T_{g}$ is the glass transition temperature (c.f. Bergman and Swenson, 2000)

dielectric properties of the clay soil. The $0.7 \mathrm{~L}$ line shows an almost linear decrease for $\varepsilon_{\text {r.eff }}^{\prime}$. Only the lower part is somewhat flattened. We suggest that the permittivity of the bound water $\varepsilon_{\mathrm{W}}$ approaches the permittivity of the solid particles $\varepsilon_{\mathrm{G}}$. Hence, the permittivity of the soil $\varepsilon_{\mathrm{r}, \text { eff }}^{*}$ decreases. There is no evidence indicating ice formation. The same results for the $1.17 \mathrm{~L}$ line except that the higher water content extends the linear part of the permittivity down to $-70^{\circ} \mathrm{C}$. Only the stronger decrease of the $1.53 \mathrm{~L}$ line below $0^{\circ} \mathrm{C}$ could be an indication of ice formation.

Figure 11 shows the temperature dependence of $\varepsilon_{\text {reff }}^{\prime}$ for 1.37, 1.71 and 1.96 monolayers water on JSC Mars 1 at the same frequency of $350 \mathrm{kHz}$. The $\varepsilon_{\mathrm{r}, \text { eff }}$ values showed also the lowest dielectric losses at this frequency. The $1.96 \mathrm{~L}$ line shows, like the $1.71 \mathrm{~L}$ line, an almost linear decrease of the permittivity over the whole temperature range. In contrast the $1.37 \mathrm{~L}$ line decreases linearly up to approximately $-20^{\circ} \mathrm{C}$, turns into a plateau phase and then continues to decrease from approximately $-50{ }^{\circ} \mathrm{C}$. At the plateau, the dielectric behaviour of dry soil could already dominate the processes. Evidence for ice formation at the three curves was not detected.
Both soils, clay and JSC Mars 1 have not shown indications for freezing except the $1.53 \mathrm{~L}$ line of the clay soil in Fig. 10. Either the water remains in a liquid state or the effect of ice formation is overlaid by other polarization effects. In both soils the permittivity decreases for temperatures greater than $0{ }^{\circ} \mathrm{C}$. This "temperature effect" has already been described by Stacheder (1996). The 1.53 L line of the clay soil was analysed in Sect. 5.2. Interfacial water content below $0{ }^{\circ} \mathrm{C}$ could be calculated and ice formation substantiated. For all other water contents in this paper, the water likely remains in the liquid-like state down to $-70^{\circ} \mathrm{C}$.

\section{Discussion}

High-frequency electromagnetic measurements techniques for in situ soil moisture estimation such as time domain reflectometry (TDR) are mostly based on an empirical relationship between measured apparent permittivity $\varepsilon_{\text {app }}$ and volumetric water content (e.g. Topp et al., 1980). Under this circumstance, these techniques assume a slight temperature dependence of $\varepsilon_{\text {app }}$ in the temperature range above $0^{\circ} \mathrm{C}$, which is a justified assumption for specific soils (e.g. Stacheder, 


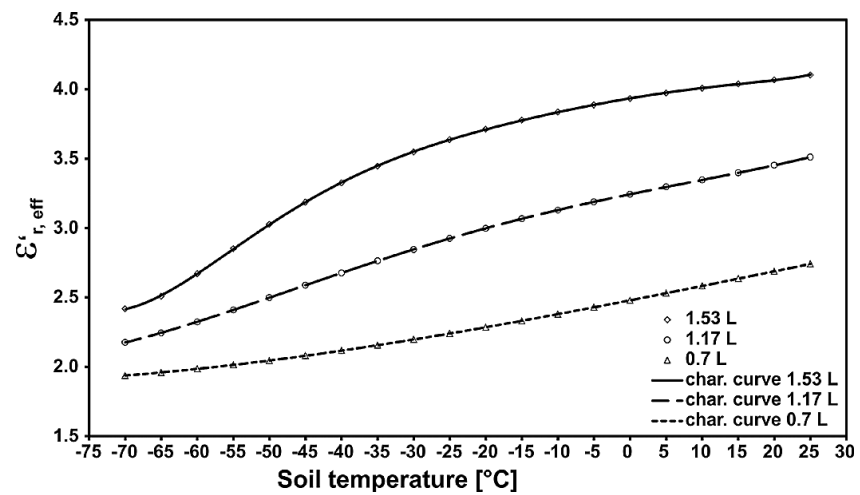

Fig. 10. Dependence of $\varepsilon_{\mathrm{r}, \text { eff }}^{\prime}$ for the clay soil at $350 \mathrm{kHz}$ for 0.7 , 1.17 and 1.53 monolayers water (1) in a temperature range from -70 to $25^{\circ} \mathrm{C}$.

1996). For this reason, the decrease of $\varepsilon_{\text {app }}$ below $0{ }^{\circ} \mathrm{C}$ is solely ascribed to the freezing of liquid water. Therefore, measured permittivity is assumed to be a function of the volume fraction of soil and the residual liquid water. This simplified calculation leads to incorrect results (Yoshikawa and Overduin, 2005) also because below $0{ }^{\circ} \mathrm{C}$, the liquid water content depends on the total water content of the soil sample (Oliphant, 1985). However, Seyfried and Murdock (1996) investigated the differences between experimental data obtained with empirical equations or theoretical mixing models such as the CRIM equation (12) based on TDR measurements. The results confirm the dependence of the liquid water content below $0{ }^{\circ} \mathrm{C}$ on the total water content. Reliable conclusions for the differences between experimental data and theoretical models were not drawn by Seyfried and Murdock (1996).

On the other hand, theoretical models based on the Claypeyron equation (cf. Seyfried and Murdock, 1996) or the sandwich model (Sect. 2.1) provide a physical theory for the calculation of the interfacial water content and show no dependence on the total water content. These findings were further supported by the empirical approach for interfacial water contents below $0{ }^{\circ} \mathrm{C}$ suggested by Anderson and Tice (1973):

$$
\begin{aligned}
\ln (w) & =0.2618+0.5519 \cdot \ln \left(S_{\mathrm{sp}}\right) \\
& -1.449 \cdot S_{\mathrm{sp}}^{-0.264} \cdot \ln \left(T_{\mathrm{m}}-T_{\mathrm{S}}\right) .
\end{aligned}
$$

Hence, for swelling clays, the mentioned calculations by Seyfried and Murdock (1996) consequently have resulted to incorrect results due to neglecting the temperature effect (Sect. 4). This further suggests to be the reason for the unsatisfying results in the determination of ice contents in clays by Bittelli et al. (2004).

In Sect. 5.2 a new approach for simultaneous ice and liquid water content estimation in soils based on experimental data from the clay soil will be introduced (Lorek, 2008). This approach explicitly takes the temperature effect into account.

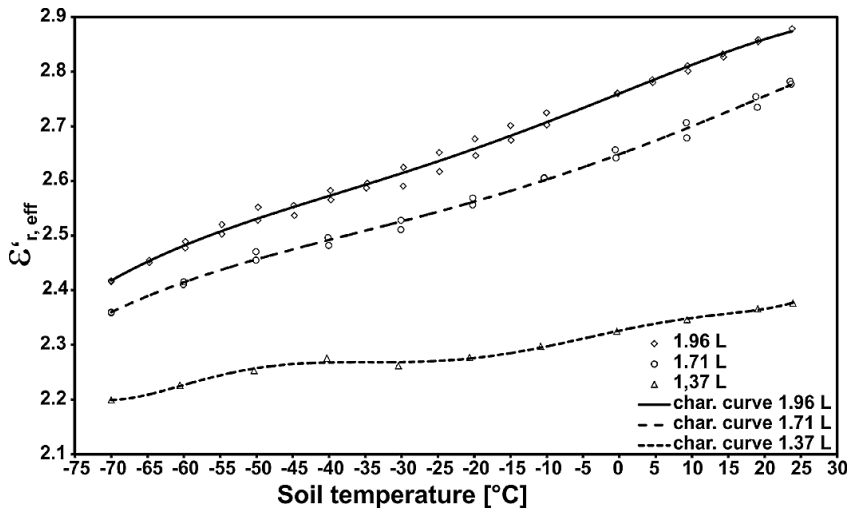

Fig. 11. Temperature dependence of $\varepsilon_{\text {r,eff }}^{\prime}$ for JSC Mars 1 at $350 \mathrm{kHz}$ for $1.37,1.71$ and 1.96 monolayers of water (l) in the range from -70 to $25^{\circ} \mathrm{C}$.

The ice and water content of the clay soil was then estimated with the CRIM or Birchak equation (12) for the $1.53 \mathrm{~L}$ line in Fig. 10. However, appropriate soil parameters in Eq. (13) have to be determined prior to the application of Eq. (9).

\subsection{Estimation of the solid-phase permittivity $\varepsilon_{G}$}

In Table 4 the permittivity of the solid phase of the clay soil and JSC Mars 1 are summarized. The values were either calculated using formulas of Dobson et al. (1985), Olhoeft et al. (1975) and Campbell (2002) or taken from literature.

The measured permittivity $\varepsilon_{\mathrm{r}, \mathrm{eff}}^{\prime}$ of the clay soil and JSC Mars 1 at the lowest water contents of 0.179 and 0.314 monolayers are 1.803 and 1.994, respectively (Fig. 12). The appropriate volume fractions were calculated with the equation

$\Theta_{\mathrm{G}}=m_{\mathrm{G}} \cdot S_{\mathrm{sp}} / \theta_{\mathrm{Soil}}$

and

$\Theta_{\mathrm{W}}=d_{1} /\left((4 \cdot S \cdot l \cdot v) /\left(\pi \cdot d_{3}^{2}\right)\right)$.

The resulting volume fractions are $\Theta_{A}=0.6838 \mathrm{~m}^{3} \mathrm{~m}^{-3}$, $\Theta_{\mathrm{W}}=0.0107 \mathrm{~m}^{3} \mathrm{~m}^{-3}$ and $\Theta_{\mathrm{G}}=0.3055 \mathrm{~m}^{3} \mathrm{~m}^{-3}$ for the clay soil and $\Theta_{A}=0.7077 \mathrm{~m}^{3} \mathrm{~m}^{-3}, \Theta_{\mathrm{W}}=0.0139 \mathrm{~m}^{3} \mathrm{~m}^{-3}$ and $\Theta_{\mathrm{G}}=0.2784 \mathrm{~m}^{3} \mathrm{~m}^{-3}$ for JSC Mars 1 . For the dry clay soil a $\varepsilon_{\mathrm{G}}$ value of 4.33 was calculated with Eq. (13). The calculated $\varepsilon_{\mathrm{G}}$ value for dry JSC Mars 1 is 5.87. These values are in reasonable accordance with the data in Table 3 and support the reliability of the approach.

\subsection{Estimation of the ice and liquid water content of the clay soil below $0{ }^{\circ} \mathrm{C}$}

Figure 13 illustrates the calculated $\varepsilon_{\mathrm{W}}^{\prime}$ curve for $0.7,1.17$ and 1.53 monolayers water based on Eq. (13). For decreasing temperatures above $0{ }^{\circ} \mathrm{C}$ the permittivity falls in all three cases nearly linear. This can be explained by the temperature effect mentioned in Sect. 4 through which lower water 


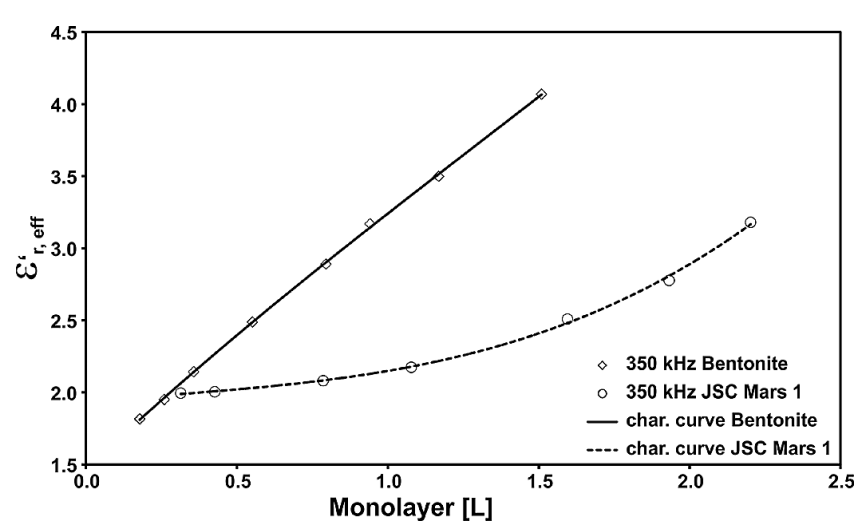

Fig. 12. Characteristic curve of $\varepsilon_{\text {r,eff }}^{\prime}$ with respect to the moisture of the clay soil and JSC Mars 1 at a frequency of $350 \mathrm{kHz}$ and $25^{\circ} \mathrm{C}$.

content leads to a stronger decrease of the permittivity. The $0.7 \mathrm{~L}$ curve shows the strongest decrease with a flatter line at lower temperatures. This behaviour is supposed to be associated with the reduced influence of the temperature effect with decreasing number of monolayers. The $1.17 \mathrm{~L}$ curve has down to $-55^{\circ} \mathrm{C}$ an almost linear decrease. The $1.53 \mathrm{~L}$ curve shows a different behaviour with a stronger decrease below $0{ }^{\circ} \mathrm{C}$ which suggests a phase transition.

To determine the ice content in the soil based on available data of $\varepsilon_{\mathrm{W}}^{\prime}$, it is necessary to estimate the permittivity $\varepsilon_{\text {IW }}^{\prime}$ of bound water or (without freezing) interfacial water. Assuming supercooling of all available water (without ice formation) below $0{ }^{\circ} \mathrm{C}$ the decrease of the $\varepsilon_{\text {IW }}^{\prime}$ values for dropping temperature is further linear, the known linear decrease can be used for temperatures below $0{ }^{\circ} \mathrm{C}$. Due to the lack of experimental data of the electromagnetic properties of interfacial water, the $\varepsilon_{\text {IW }}^{\prime}$ values between the $0.7,1.17$ and $1.53 \mathrm{~L}$ lines have been extrapolated from temperatures above $0{ }^{\circ} \mathrm{C}$. Using the assumption stated before, the determined decreases are extended down to lower temperatures and represent thereby the permittivity of the interfacial water content for different monolayers. Figure 14 shows the calculated curves from Fig. 13 compared to the deduced curves without ice formation.

To calculate the content of ice and liquid-like water, the term $\left(\Theta_{\mathrm{W}} \cdot \varepsilon_{\mathrm{W}}^{0.5}\right)$ in Eq. (12) has been separated into parts for interfacial water $\left(\Theta_{\mathrm{IW}} \cdot \varepsilon_{\mathrm{IW}}^{0.5}\right)$ and ice $\left(\Theta_{I} \cdot \varepsilon_{I}^{0.5}\right)$ :

$\varepsilon_{\mathrm{r}, \mathrm{eff}}^{0.5}=\Theta_{\mathrm{G}} \cdot \varepsilon_{\mathrm{G}}^{0.5}+\Theta_{A} \cdot \varepsilon_{A}^{0.5}+\Theta_{\mathrm{IW}} \cdot \varepsilon_{\mathrm{IW}}^{0.5}+\Theta_{I} \cdot \varepsilon_{I}^{0.5}$.

The characteristics shown in Fig. 10 are expected to be reproduced using Eq. (23). The values $\varepsilon_{\mathrm{G}}$, $\Theta_{\mathrm{G}}$ (Sect. 5.1) and $\varepsilon_{A}$ (Sect. 2.2) are known. The permittivity of polycrystalline isotropic ice at $350 \mathrm{kHz}$ with $\varepsilon_{I}=3.22$ was estimated from experimental data of the permittivity tensor provided in Bohleber et al. (2012). The values for $\varepsilon_{\text {IW }}, \Theta_{\text {IW }}, \Theta_{A}$ and $\Theta_{I}$ were obtained as described in the following scheme. For this purpose the $1.53 \mathrm{~L}$ line (solid line) and the $1.32 \mathrm{~L}$ line

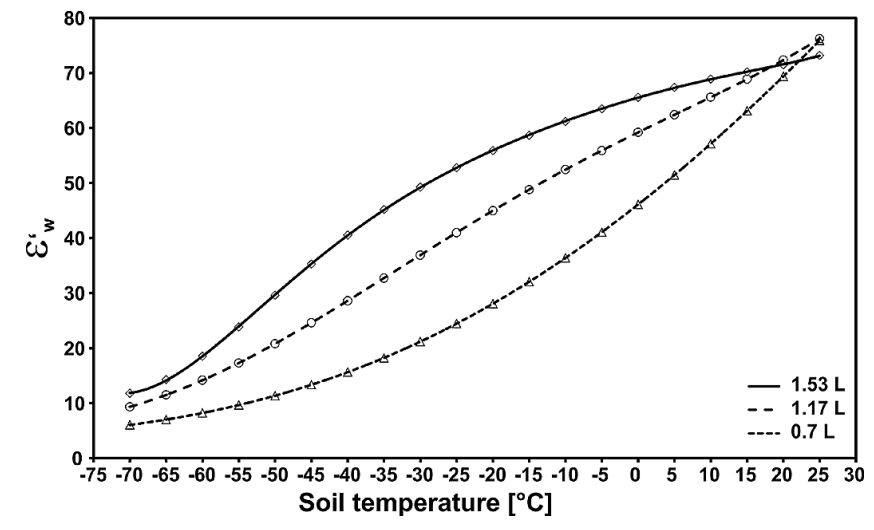

Fig. 13. Calculated real part $\varepsilon_{\mathrm{W}}^{\prime}$ of the bound water $\varepsilon_{\mathrm{W}}$ for $0.7,1.17$ and 1.53 water monolayers for the clay soil in a temperature range from -70 to $25^{\circ} \mathrm{C}$.

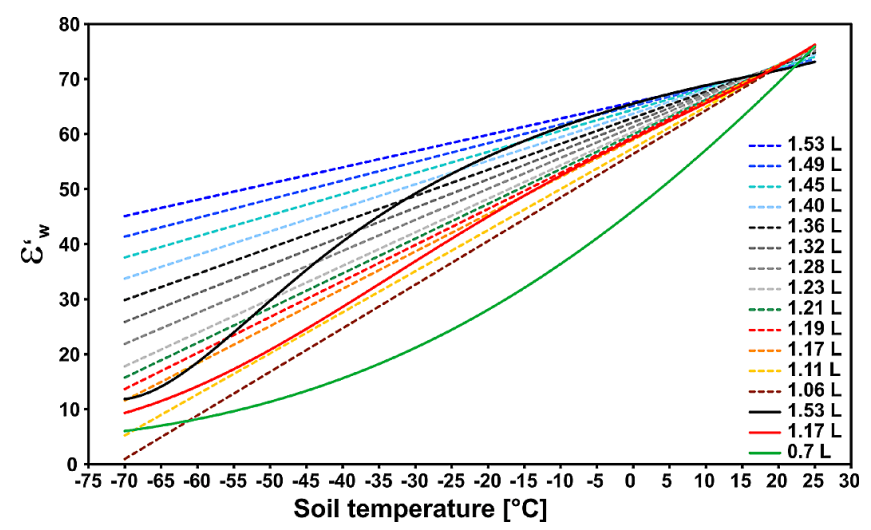

Fig. 14. Figure 13 with deduced linear $\varepsilon_{\mathrm{flW}}$ curves representing the permittivity of interfacial water (linear dotted lines).

(dotted line) in Fig. 14 were considered. The $1.32 \mathrm{~L}$ line generates the $\Theta_{\text {IW }}$ value (cf. Sect. 5.1), while the monolayer difference to the $1.53 \mathrm{~L}$ line gives the $\Theta_{I}$ value. $\Theta_{A}$ was then determined by $\Theta_{A}=1-\Theta_{\mathrm{G}}-\Theta_{\mathrm{IW}}-\Theta_{I}$. Thereafter, the remaining $\varepsilon_{\text {IW }}$ value were calculated with Eq. (23). In Table 5, the calculated results are compiled. The obtained data set of the described example are marked in grey.

The results obtained with the described scheme are in reasonable agreement with the measured 1.5 monolayers of supercooled water at $-30^{\circ} \mathrm{C}$ for the clay soil by Grimm et al. (2007) using NMR (Sect. 1). Figure 15 illustrates the results for the interfacial water monolayer from Table 5 in comparison with the sandwich model (Sect. 2.1). The Hamaker constant of $1.01 \times 10^{-19} \mathrm{~J}$, calculated with Eq. (1), is in the expected order of magnitude from $10^{-19}$ to $10^{-20} \mathrm{~J}$ (Möhlmann, 2008; Watanabe and Mizoguchi, 2002). The resulting monolayer of interfacial water in respect to the temperature (Eq. 1) is shown in Fig. 15.

In the range from -70 to $-40^{\circ} \mathrm{C}$ the values in Table 5 are almost identical to those obtained with the sandwich model. Based on this observation, the described method to determine 
Table 4. Summary of the solid-phase permittivity $\varepsilon_{\mathrm{G}}$ (cf. Lorek, 2008).

\begin{tabular}{lllll}
\hline Literature & Material & $\begin{array}{l}\text { Spec. frequency } \\
\text { density }\end{array}$ & $\varepsilon_{\mathrm{G}}$ & \\
\hline Dobson formula & clay/JSC Mars 1 & $2.38 \mathrm{~g} \mathrm{~cm}^{-3} / 2.64 \mathrm{~g} \mathrm{~cm}^{-3}$ & $1.4-18 \mathrm{GHz}$ & $4.18 / 4.65$ \\
Olhoeft formula & clay/JSC Mars 1 & $2.38 \mathrm{~g} \mathrm{~cm}^{-3} / 2.64 \mathrm{~g} \mathrm{~cm}^{-3}$ & $>100 \mathrm{kHz}$ & $4.78 / 5.67$ \\
Campbell formula & clay/JSC Mars 1 & $2.38 \mathrm{~g} \mathrm{~cm}^{-3} / 2.64 \mathrm{~g} \mathrm{~cm}^{-3}$ & - & $4.96 / 5.91$ \\
Robinson (2004a) & montmorillonite & $2.67 \mathrm{~g} \mathrm{~cm}^{-3}$ & $0.001-1.75 \mathrm{GHz}$ & 5.5 \\
\hline
\end{tabular}

Table 5. Ice and liquid water content of the clay soil, permittivity $\varepsilon_{\mathrm{IW}}$ and $\varepsilon_{\text {r,eff }}$ based on the $1.53 \mathrm{~L}$ line (Figs. 10 and 14) and Eq. (23).

\begin{tabular}{ccccc}
\hline \multirow{2}{*}{$\begin{array}{c}\text { Temperature } \\
{ }^{\circ} \mathrm{S}\end{array}$} & \multicolumn{3}{c}{ Monolayer } & \\
\cline { 2 - 3 }$\left({ }^{\circ} \mathrm{C}\right)$ & Water & Ice & $\varepsilon_{\text {IW }}$ & $\varepsilon_{\text {r,eff }}$ \\
\hline 0 & 1.53 & 0.00 & 65.76 & 3.93 \\
-19 & 1.49 & 0.04 & 58.68 & 3.72 \\
-31 & 1.45 & 0.09 & 52.55 & 3.53 \\
-39 & 1.40 & 0.13 & 47.01 & 3.35 \\
-45 & 1.36 & 0.17 & 41.66 & 3.19 \\
-50 & 1.32 & 0.21 & 36.24 & 3.02 \\
-55 & 1.28 & 0.26 & 30.31 & 2.85 \\
-60 & 1.23 & 0.30 & 23.88 & 2.67 \\
-64 & 1.21 & 0.32 & 19.53 & 2.54 \\
-68 & 1.19 & 0.34 & 14.98 & 2.44 \\
\hline
\end{tabular}

the content of ice and liquid water should be a good approach. The similar result for the liquid water content from the Anderson and Tice equation (20) supports this conclusion.

\section{Conclusions}

A parallel plate capacitor has been developed to obtain isothermal dielectric spectra of fine-grained soils in the frequency range from $10 \mathrm{~Hz}$ to $1.1 \mathrm{MHz}$ at Martian-like temperatures down to $-70^{\circ} \mathrm{C}$ (Lorek, 2008). Two Martian analogue soils have been investigated: a Ca-bentonite (specific surface of $237 \mathrm{~m}^{2} \mathrm{~g}^{-1}$, up to $9.4 \% \mathrm{w} / \mathrm{w}$ gravimetric water content) and JSC Mars 1, a volcanic ash (specific surface of $146 \mathrm{~m}^{2} \mathrm{~g}^{-1}$, up to $7.4 \% \mathrm{w} / \mathrm{w}$ ). The dielectric relaxation behaviour was analysed with three different methods: (i) based on the temperature dependence of characteristic frequencies such as the maximum frequency in the imaginary part of the complex effective permittivity, (ii) based on the inverse modelling technique by means of fitting the frequency dependency of the complex permittivity at each measured temperature, and (iii) a simultaneous fit of the frequency and temperature dependence.

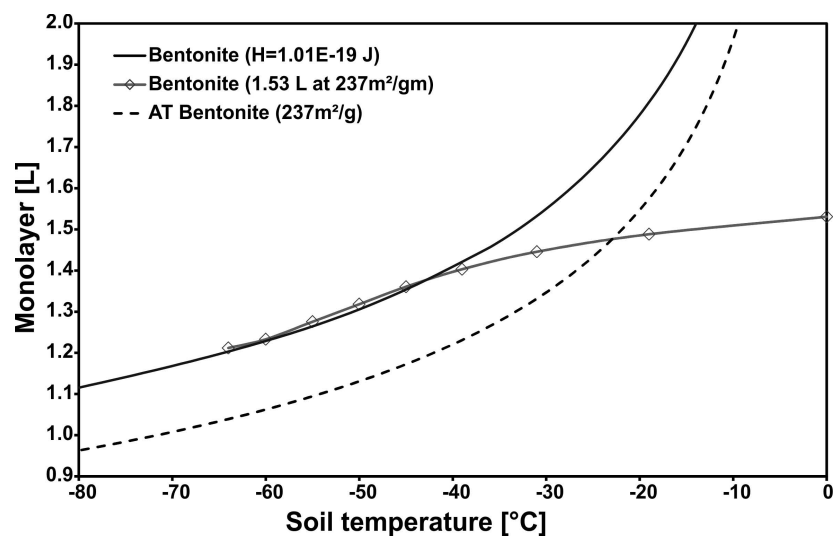

Fig. 15. Interfacial water content of the clay soil based on the sandwich model (black solid line), the deduced values of the $1.53 \mathrm{~L}$ line from Table 5 (grey line) and the Anderson-Tice equation (20) (dotted line).

The experimental results indicate three active relaxation processes in the investigated frequency-temperaturepressure range: two weak high-frequency processes $\alpha$ and $\beta$ (associated with different binding states of water in the porous material) and a strong low-frequency process $\gamma$ associated with counter-ion relaxation, Maxwell-Wagner effects and ice. To characterize the dielectric relaxation behaviour, a generalized fractional dielectric relaxation model (Wagner et al., 2007, 2011) was applied assuming three active relaxation processes with relaxation time of the $i$ th process modelled with an Eyring equation (Wagner and Scheuermann, 2009). The strong $\gamma$ process exhibits an apparent activation energy of $51 \mathrm{~kJ} \mathrm{~mol}^{-1}$ and shows a clear deviation from simple Debye behaviour. This is a clear indication of an overlapping of different relaxation mechanisms. Furthermore, the analysis of the relaxation behaviour indicates an increase of the relaxation time distribution with decreasing temperature, which suggests that the relaxation time distribution is a measure of the coexistence of liquid-like water and ice. The $\beta$ process is visible in the low-temperature range below $-50^{\circ} \mathrm{C}$ with apparent activation energy of $41 \mathrm{~kJ} \mathrm{~mol}^{-1}$. For an analysis of the $\alpha$ process, the frequency range has to be extended to higher frequencies. However, based on the inverse modelling technique, appropriate apparent activation energy of 
$32 \mathrm{~kJ} \mathrm{~mol}^{-1}$ was estimated. Furthermore, a narrow relaxation time distribution was observed.

The real part of effective relative complex soil permittivity at $350 \mathrm{kHz}$ was used to determine ice and liquid-like water content by means of the CRIM or Birchak equation (Lorek, 2008). There is evidence that, down to $-70^{\circ} \mathrm{C}$, swelling clay soil (Ca-bentonite) has an interfacial water content of 1.17 monolayers and JSC Mars 1 has an interfacial water content of 1.96 monolayers. The results of the experimental investigations as well as the analysis show that the technique is suitable to estimate liquid-like water content in soils below $0{ }^{\circ} \mathrm{C}$. The results of the investigated Martian analogue soils generally confirm the sandwich model for interfacial water.

Based on the measurement and analysis strategy combined with the theoretical model (Sect. 2.1), the thickness of the liquid water layer in the soil can be predicted (or estimated) for temperatures below $0{ }^{\circ} \mathrm{C}$. Hence, the results provide new concepts for an improved assessment of the water exchange between Mars' atmosphere and regolith and the rheological properties. They are also important for Mars-relevant biological experiments or the development of in situ measurement devices as part of the scientific payload on missions to Mars. The knowledge of the liquid-like water content below $0{ }^{\circ} \mathrm{C}$ is also important for the rheological properties of permafrost soils, especially for the prediction of mudslides and debris avalanches in alpine regions. However, there is the need to (1) systematically analyse soils with variation in texture and structure as well as mineralogy, (2) broaden the frequency range to lower $(\approx 1 \mathrm{~Hz})$ and higher frequencies $(\approx 10 \mathrm{GHz})$, and $(3)$ study the influence of the chemical reactions in the aqueous pore solution on the relaxation dynamics of porous materials, (4) thereby assessing the dielectric relaxation behaviour of equivalent pore solutions under defined temperature-pressure conditions.

Acknowledgements. We would like to thank David Wolter and Hendrik Hansen-Goos for many valuable suggestions and corrections to this manuscript. Moreover, the authors gratefully acknowledge the German Research Foundation (DFG) for providing financial support to N. Wagner through the project Wa 2112/2-1.

The service charges for this open access publication

have been covered by a Research Centre of the

Helmholtz Association.

Edited by: J. Boike

\section{References}

Agilent: Agilent 16451B Dielectric Test Fixture, Operation and Service Manual, Manual Identification: Model Number 16451B; Data Printed Oct. 2000, Part Number 16451-90020, 2000.

Allen, C. C., Morris, R. V., Jager, K. M., Golden, D. C., Lindstrom, D. J., Lindstrom, M. M., and Lockwood, J. P.: Martian re- golith simulant JSC MARS-1. Presented at the 29th Annual Lunar and Planetary Science Conference, LPI, Houston, TX, 1998.

Anderson, D. M. and Tice, A. R.: The unfrozen water and the apparent specific heat capacity of frozen soils, in: Permafrost: North American Contribution [to The] Second International Conference. Presented at the 2nd International Conference on Permafrost, National Academy of Sciences, Washington, 1973.

Auty, R. P. and Cole, R. H.: Dielectric properties of ice and solid D2 O, J. Chem. Phys., 20, 1309-1314, 1952.

Behari, J.: MicroWave Dielectric Behavior of Wet Soils, Springer, Anamaya, New York, New Delhi, 2005.

Birchak, J. R., Gardner, C. G., Hipp, J. E., and Victor, J. M.: High dielectric constant microwave probes for sensing soil moisture, P. IEEE, 62, 93-98, 1974.

Bittelli, M., Flury, M., and Roth, K.: Use of dielectric spectroscopy to estimate ice content in frozen porous media, Water Resour. Res., 40, 1-11, 2004.

Bohleber, P., Wagner, N., and Eisen, O.: Permittivity of ice at radio frequencies: Part I: Coaxial transmission line cell, Cold Reg. Sci. Technol., 82, 56-67, 2012.

Buchner, R., Barthel, J., and Stauber, J.: The dielectric relaxation of water between $0{ }^{\circ} \mathrm{C}$ and $35^{\circ} \mathrm{C}$, Chem. Phys. Lett., 306, 57-63, 1999.

Buehler, M., Cobos, D., and Dunne, K.: Dielectric constant and Osmotic Potential from Ion-Dipole Polarization Measurements of $\mathrm{KCl}$ and $\mathrm{NaCldoped} \mathrm{Aqueos} \mathrm{solutions,} \mathrm{ISEMA} \mathrm{Proceedings,}$ June 2011.

Calvet, R.: Dielectric properties of montmorillonites saturated by bivalent cation s, Clay Clay Miner., 23, 257-265, 1975.

Campbell, B. A.: Radar Remote Sensing of Planetary Surfaces, Cambridge University Press, Cambridge, 2002.

Campbell, J. E.: Dielectric properties and influence of conductivity in soils at one to fifty megahertz, Soil Sci. Soc. Am. J., 54, 332341, 1990.

Chaplin, M.: Water properties, including heavy water data, Water Structure and Scienc E, http://www.lsbu.ac.uk/water/data.html (last access: 23 November), 2012.

Chevrier, V. and Mathe, P.: Mineralogy and evolution of the surface of Mars: a review, Planet. Space Sci., 55, 289-314, 2007.

Dash, J., Rempel, A., and Wettlaufer, J.: The physics of premelted ice and its geophysical consequences, Rev. Mod. Phys., 78, 695741, 2006.

Delaney, A. J. and Arcone, S. A.: Dielectric measurements of frozen silt using time domain reflectometry, Cold Reg. Sci. Technol., 9, 39-46, 1984.

Dirksen, C. and Dasberg, S.: Improved calibration of time domain reflectometry soil water content measurements, Soil Sci. Soc. Am. J., 57, 660-667, 1993.

Dobson, M., Ulaby, F., Hallikainen, M., and El-rayes, M.: Microwave dielectric behavior of wet soil: Part II: Dielectric mixing models, IEEE T. Geosci. Remote, 23, 35-46, 1985.

Eisen, O., Nixdorf, U., Keck, L., and Wagenbach, D.: Alpine ice cores and ground penetrating radar: combined investigations for glaciological and climatic interpretations of a cold Alpine ice body, Tellus B, 55, 1007-1017, 2003.

Eisen, O., Wilhelms, F., Steinhage, D., and Schwander, J.: Improved method to determine radio-echo sounding reflector depths from ice-core profiles of permittivity and conductivity, J. Glaciol., 52, 299-310, 2006. 
Feldman, W. C.: Global distribution of near-surface hydrogen on Mars, J. Geophys. Res., 109, 1-13, 2004.

Grimm, R. E., Stillman, D. E., Dec, S. F., and Bullock, M. A.: Lowfrequency electrical properties of polycrystalline saline ice and salt hydrates, J. Phys. Chem. B, 112, 15382-15390, 2008.

Hamaker, H. C.: The London-van der Waals attraction between spherical particles, Physica, 4, 1058-1072, 1937.

Hasted, J. B.: Aqueous dielectrics, Chapman \& Hall, 1973.

Hauffe, K. and Morrison, S. R.: Adsorption: Eine Einführung in die Probleme der Adsorption, Walter de Gruyter, Berlin, 1974.

Heimovaara, T. J., Huisman, J. A., Vrugt, J. A., and Bouten, W.: Obtaining the spatial distribution of water content along a TDR probe using the SCEM-UA bayesian inverse modeling scheme, Vadose Zone J., 3, 1128-1145, 2004.

Hoekstra, P. and Doyle, W.: Dielectric relaxation of surface adsorbed water, J. Colloid Interf. Sci., 36, 513-521, 1971.

Huisman, J. A., Hubbard, S. S., Redman, J. D., and Annan, A. P.: Measuring soil water content with ground penetrating radar: a review, Vadose Zone J., 2, 476-491, 2003.

Ito, N. and Richert, R.: Effect of dispersion on the relaxationretardation time scale ratio, J. Chem. Phys., 123, 106101, 2005.

Ishida, T., Makino, T., and Wang, C.: Dielectric-relaxation spectroscopy of kaolinite, montmorillonite, allophane, and imogolite under moist condition s, Clay Clay Miner., 48, 75-84, 2000.

Ishida, T., Kawase, M., Yagi, K., Yamakawa, J., and Fukada, K.: Effects of the counterion on dielectric spectroscopy of a montmorillonite suspension over the frequency range $105-1010 \mathrm{~Hz}$, J. Colloid Interf. Sci., 268, 121-126, 2003.

Jänchen, J., Morris, R. V., Bish, D. L., and Hellwig, U.: The $\mathrm{H}_{2} \mathrm{O}$ Sorption Properties of a Martian Dust Analog, in: Lunar and Planetary Science XL, Presented at the 40th Lunar and Planetary Science Conference, The Woodlands, Texas, 2009a.

Jänchen, J., Morris, R. V., Bish, D. L., Janssen, M., and Hellwig, U.: The $\mathrm{H}_{2} \mathrm{O}$ and $\mathrm{CO}_{2}$ adsorption properties of phyllosilicate-poor palagonitic dust and smectites under martian environmental conditions, Icarus, 200, 463-467, 2009b.

Jonscher, A.: Dielectric relaxation in solids, Chelsea Dielectric, London, 1983.

Kaatze, U.: Non-conducting and conducting reference liquids for the calibration of dielectric measurement systems, in: Proc. of the 7th International Conference on Electromagnetic Wave Interaction with Water and Moist Substances, Presented at the ISEMA, Okamura, 2007a.

Kaatze, U.: Reference liquids for the calibration of dielectric sensors and measurement instruments, Meas. Sci. Technol., 18, 967976, 2007b.

Kaatze, U. and Feldman, Y.: Broadband dielectric spectrometry of liquids and biosystems, Meas. Sci. Technol., 17, 17-35, 2006.

Kereszturi, A., Möhlmann, D., Berczi, S., Ganti, T., Horvath, A., Kuti, A., Pocs, T., and Szathmary, E.: Analysis of Possible Interfacial Water Driven Seepages on Mars, in: Lunar and Planetary Science XXXIX, Presented at the 39th Lunar and Planetary Science Conference, League City, Texas, 1555 pp., 2008.

Kereszturi, A., Möhlmann, D., Berczi, S., Ganti, T., Horvath, A., Kuti, A., Sik, A., and Szathmary, E.: Indications of brine related local seepage phenomena on the Northern Hemisphere of Mars, Icarus, 207, 149-164, 2010.

Kupfer, K., International Conference on Electromagnetic Wave Interaction with Water and Moist Substances: Electromagnetic aquametry electromagnetic wave interaction with water and moist substances, Springer, Berlin, New York, 2005.

Landau, L. D. and Lifshitz, E. M.: Elektrodynamik der Kontinua, Akademie Verlag, Berlin, 1993.

Leroy, P., Revil, A., Kemna, A., Cosenza, P., and Ghorbani, A.: Complex conductivity of water-saturated packs of glass beads, J. Colloid and Interf. Sci., 321, 103-117, 2008.

Loeffler, O. and Bano, M.: Ground penetrating radar measurements in a controlled Vadose Zone: influence of the water content, Vadose Zone J., 3, 1082-1092, 2004.

Lorek, A.: Flüssiges unterkühltes Grenzflächenwasser in der Marsoberfläche, Dissertation, University-Potsdam/DLR, 2008.

Maeno, N., Araki, T., Moore, J., and Fukuda, M.: Dielectric response of water and ice in frozen soils, in: Physics and Chemistry of Ice, edited by: Maeno, N. and Hondoh, T., 381-386, Hokkaido University Press, Hokkaido, 1992.

Merriam, J. B.: Induced polarization and surface electrochemistry, Geophysics, 72, 157-166, 2007.

Mironov, V. L., Dobson, M. C., Kaupp, V. H., Komarov, S. A., and Kleshchenko, V. N.: Generalized refractive mixing dielectric model for moist soils, IEEE T. Geosci. Remote, 42, 773-785, 2004.

Mironov, V. L., De Roo, R. D., and Savin, I. V.: Temperaturedependable microwave dielectric model for an arctic soil, IEEE T. Geosci. Remote, 48, 2544-2556, 2010.

Möhlmann, D.: Water in the upper martian surface at mid- and lowlatitudes: presence, state, and consequences, Icarus, 168, 318323, 2004.

Möhlmann, D.: The influence of van der Waals forces on the state of water in the shallow subsurface of Mars, Icarus, 195, 131-139, 2008.

Möhlmann, D., Niemand, M., Formisano, V., Savijärvi, H., and Wolkenberg, P.: Fog phenomena on Mars, Planet. Space Sci., 57, 1987-1992, 2009.

Olhoeft, G. R.: Electrical properties of rocks, in: The Physics and Chemistry of Minerals and Rocks, John Wiley and Sons, London, 261-278, 1974.

Olhoeft, G. R., Strangway, D. W., and Pearce, G. W.: Effects of water on electrical properties of lunar fines, in: Proceeding of the Sixth Annual Lunar Science Conference, Lunar and Planetary Institute, Pergamon Press, Houston, TX, 3333-3442, 1975.

Oliphant, J. L.: A model for dielectric constants of frozen soils, I freezing and thawing of soil-water systems, 1985.

Or, D. and Wraith, J. : Temperature effects on soil bulk dielectric permittivity measured by time domain reflectometry: A physical model, Water Resour. Res., 35, 371-383, 1999.

Picardi, G., Biccari, D., Seu, R., Marinangeli, L., Johnson, W. T. K., Jordan, R. L., Plaut, J., Safaenili, A., Gurnett, D. A., Ori, G. G., Orosei, R., Calabrese, D., and Zampolini, E.: Performance and surface scattering models for the Mars Advanced Radar for Subsurface and Ionosphere Sounding (MARSIS), Planet. Space Sci. 52, 149-156, 2004.

Podgornik, R., Cevc, G., and Žekš, B.: Solvent structure effects in the macroscopic theory of van der Waals forces, J. Chem. Phys., 87, 5957, doi:10.1063/1.453519, 1987.

Poulet, F., Bibring, J.-P., Mustard, J. F., Gendrin, A., Mangold, N., Langevin, Y., Arvidson, R. E., Gondet, B., Gomez, C., Berthé, M., Bibring, J.-P., Langevin, Y., Erard, S., Forni, O., Gendrin, A., Gondet, B., Manaud, N., Poulet, F., Poulleau, G., Souf- 
flot, A., Combes, M., Drossart, P., Encrenaz, T., Fouchet, T., Melchiorri, R., Bellucci, G., Altieri, F., Formisano, V., Fonti, S., Capaccioni, F., Cerroni, P., Coradini, A., Korablev, O., Kottsov, V., Ignatiev, N., Titov, D., Zasova, L., Mangold, N., Pinet, P., Schmitt, B., Sotin, C., Hauber, E., Hoffmann, H., Jaumann, R., Keller, U., Arvidson, R., Mustard, J., and Forget, F.: Phyllosilicates on Mars and implications for early martian climate, Nature, 438, 623-627, 2005.

PVDF: PVDF Technisches Datenblatt, 2003.

Richert, R.: Scaling vs. Vogel-Fulcher-type structural relaxation in deeply supercooled materials, Physica A Stat. Mech. Appl., 287 (1), 26-36, 2000.

RALICKS: Dichtungs-Werkstoffe, Dichtungs-Werkstoff-Übersicht und Eigenschaften, 2012.

Rivkina, E. M., Friedmann, E. I., McKay, C. P., and Gilichinsky, D. A.: Metabolic activity of permafrost bacteria below the freezing point, Appl. Environ. Microb., 66, 3230-3233, 2000.

Robinson, D. A. and Friedman, S. P.: A method for measuring the solid particle permittivity or electrical conductivity of rocks, sediments, and granular materials, J. Geophys. Res., 108, 2076, doi:10.1029/2001JB000691, 2003.

Robinson, D. A.: Measurement of the solid dielectric permittivity of clay minerals and granular samples using a time domain reflectometry immersion method, Vadose Zone J., 3, 705-713 2004a.

Robinson, D. A.: Calculation of the dielectric properties of temperate and tropical soil minerals from ion polarizabilities using the Clausius-Mosotti equation, Soil Sci. Soc. of Am. J., 68, 1780, doi:10.2136/sssaj2004.1780, 2004b.

Robinson, D. A., Jones, S. B., Wraith, J. M., Or, D., and Friedman, S. P.: A review of advances in dielectric and electrical conductivity measurement in soils using time domain reflectometry, Vadose Zone J., 2, 444-475, 2003.

Rost, A.: Messung dielektrischer Stoffeigenschaften, AkademieVerlag Berlin, Berlin, 1978.

Rotenberg, B., Cadéne, A., Dufrêche, J.-F., Durand-Vidal, S., Badot, J.-C., and Turq, P.: An analytical model for probing ion dynamics in clays with broadband dielectric spectroscopy, J. Physi. Chem. B, 109, 15548-15557, 2005.

Roth, K., Schulin R., Fluhler, H. and Attinger, W.: Calibration of time domain reflectometry for water content measurement using a composite dielectric approach, Water Resour. Res., 26, 22672273, 1990.

Scheffer, F. and Schachtschabel, P.: Lehrbuch der Bodenkunde, F. Enke, Stuttgart, 1989.

Schoen, J. H.: Physical properties of rocks: fundamentals and principles of petrophysics, Handbook of geophysical exploration, Seismic exploration, vol. 18, Pergamon, Oxford, UK, 1996.

Schwartz, R. C., Evett, S. R., Pelletier, M. G., and Bell, J. M.: Complex permittivity model for time domain reflectometry soil water content sensing: I. Theory, Soil Sci. Soc. Am. J., 73, 886, doi:10.2136/sssaj2008.0194, 2009.

Sciortino, F., Gallo, P., Tartaglia, P., and Chen, S.: Supercooled water and the kinetic glass transition, Phys. Rev. E, 54, 6331-6343, 1996.

Seu, R., Phillips, R. J., Alberti, G., Biccari, D., Bonaventura, F., Bortone, M., Calabrese, D., Campbell, B. A., Cartacci, M., Carter, L. M., Catallo, C., Croce, A., Croci, R., Cutigni, M., Di Placido, A., Dinardo, S., Federico, C., Flamini, E., Fois, F., Frigeri, A., Fuga, O., Giacomoni, E., Gim, Y., Guelfi, M., Holt,
J. W., Kofman, W., Leuschen, C. J., Marinangeli, L., Marras, P., Masdea, A., Mattei, S., Mecozzi, R., Milkovich, S. M., Morlupi, A., Mouginot, J., Orosei, R., Papa, C., Paterno, T., Persi del Marmo, P., Pettinelli, E., Pica, G., Picardi, G., Plaut, J. J., Provenziani, M., Putzig, N. E., Russo, F., Safaeinili, A., Salzillo, G., Santovito, M. R., Smrekar, S. E., Tattarletti, B., Vicari, D.: Accumulation and erosion of Mars' South Polar layered deposits, Science, 317, 1715-1718, 2007.

Seyfried, M. S. and Murdock, M. D.: Calibration of time domain reflectometry for measurement of liquid water in frozen soils, Soil Sci., 161, 87-98, doi:10.1250/ast.26.62, 1996.

Smith, M. D.: The annual cycle of water vapor on Mars as observed by the Thermal Emission Spectrometer, J. Geophys. Res., 107, 25, 1-19, 2002.

Speedy, R. J. and Angell, C. A.: Isothermal compressibility of supercooled water and evidence for a thermodynamic singularity at $-45^{\circ}$ C, J. Chem. Phys., 65, 851-858, 1976.

Stacheder, M.: Die Time Domain Reflectometry in der Geotechnik: Messung von Wassergehalt, elektrischer Leitfähigkeit und Stofftransport, 1996.

Stillman, D. and Olhoeft, G.: Frequency and temperature dependence in electromagnetic properties of Martian analog minerals, J. Geophys. Res., 113, 1-14, 2008.

Stillman, D. E., Grimm, R. E., and Dec, S. F.: Low-frequency electrical properties of ice-silicate mixtures, J. Phys. Chem. B, 114, 6065-6073, 2010.

Swenson, J., Bergman, R., and Longeville, S.: Experimental support for a dynamic transition of confined water, J. Non-Cryst. Solids, 307, 573-578, 2002.

Teschke, O., Ceotto, G., and De Souza, E.: Interfacial water dielectric-permittivity-profile measurements using atomic force microscopy, Phys. Rev. E., 64, 1-10, 2001.

Tieleman, D. P. and Berendsen, H. J. C.: Molecular dynamics simulations of a fully hydrated dipalmitoylphosphatidylcholine bilayer with different macroscopic boundary conditions and parameters, J. Chem. Phys., 105, 4871, doi:10.1063/1.472323, 1996.

Topp, G. C., Davis, J. L., and Annan, A. P.: Electromagnetic determination of soil water content: measurements in coaxial transmission lines, Water Resour. Res., 16, 574-582, 1980.

Ulaby, F. T., Moore, R. K., and Fung, A. K.: Microwave Remote Sensing - Active and Passive, Artech House, Dedham, MA 1986.

Viking Lander, 2: Ice on Mars Utopia Planitia Again, 1979.

Vrugt, J. A.: A S huffled Complex Evolution Metropolis algorithm for optimization and uncertainty assessment of hydrologic model parameters, Water Resour. Res., 39, 1-14, 2003.

Wagner, N. and Scheuermann, A.: On the relationship between matric potential and dielectric properties of organic free soils: a sensitivity study, Can. Geotech. J., 46, 1202-1215, 2009.

Wagner, N., Trinks, E., and Kupfer, K.: Determination of the spatial TDR-sensor characteristics in strong dispersive subsoil using 3D-FEM frequency domain simulations in combination with microwave dielectric spectroscopy, Meas. Sci. Technol., 18, 11371146, 2007.

Wagner, N., Emmerich, K., Bonitz, F., and Kupfer, K.: Experimental investigations on the frequency- and temperature-dependent dielectric material properties of soil, IEEE T. Geosci. Remote, 49, 2518-2530, 2011. 
Watanabe, K. and Mizoguchi, M.: Amount of unfrozen water in frozen porous media saturated with solution, Cold Reg. Sci. Technol., 34, 103-110, 2002.

Watanabe, K., Kito, T., Wake, T., and Sakai, M.: Freezing experiments on unsaturated sand, loam and silt loam, Ann. Glaciol., 52, 37-43, 2011.

Wernecke, R.: Industrielle Feuchtemessung: Grundlagen, Messmethoden, technische Anwendungen, Wiley-VCH, Weinheim, 2003.

Wollschläger, U., Gerhards, H., Yu, Q., and Roth, K.: Multi-channel ground-penetrating radar to explore spatial variations in thaw depth and moisture content in the active layer of a permafrost site, The Cryosphere, 4, 269-283, doi:10.5194/tc-4-269-2010, 2010 .
Yoshikawa, K. and Overduin, P. P.: Comparing unfrozen water content measurements of frozen soil using recently developed commercial sensors, Cold Reg. Sci. Technol, 42, 250-256, 2005.

Zakri, T., Laurent, J.-P., and Vauclin, M.: Theoretical evidence for "Lichtenecker's mixture formulae" based on the effective medium theory, J. Phys. D Appl. Phys., 31, 1589-1594, 1998.

Zhang, L., Shi, J. C., Zhang, Z., and Zhao, K.: The estimation of dielectric constant of frozen soil-water mixture at microwave bands, in: Proceedings of the Geoscience and Remote Sensing Symposium, IGARSS 2003 IEEE International, 21-25 July, 2903-2905, 2003. 